\title{
Evaluation of intensity augmented ICP for terrestrial LiDAR data registration
}

Sandeep Sasidharan 


\section{Need for LiDAR data registration}

- Complete 3D reconstruction

- One scan is not sufficient to obtain a full scene converge

- Transformation of all point clouds to a single coordinate system 


\section{Motivation}

- Process of LiDAR data collection

- LiDAR point cloud registration process in commercial software 


\section{Literatures on TLS data registration}

- Point to point correspondence based ICP (Besl and McKay, 1992)

- Point to plane approximations based ICP (Chen and Medoni, 1992)

- Godin et al. (1994) - using range and intensity images

- Hefford and Samson (2009) - for 2D Laser scanners

- Weinmann et al. (2011) - using feature extraction

- Altuntas (2011) - using SIFT 


\section{Literatures on TLS data registration}

- A method to incorporate the k-d tree data structure into point matching algorithm, to minimize computational time, is described in (Masuda et al., 1996).

- Hebel and Stilla (2007) propose a method for automatic registration of Laser Point Clouds from an airborne LiDAR for urban areas by incorporating the intensity of the reflected laser pulse and normal vectors of the fitted plane to attain faster convergence and higher robustness.

- The two -staged registration process presented by Weinmann et al. (2011) utilizes geometric and radiometric information, in the form of intensity images, derived from the TLS data for estimating the transformation parameters between two unregistered point clouds.

- Johnson and Kang (1997) used traditional ICP algorithm and modified it to use the color information provided by the scanner for creating virtual 3D environment. 


\section{Literature on Normalization}

- (Fang et al., 2015); (Höfle, 2014); (Teo and Yu, 2015) propose different methods to Normalize the LiDAR intensity values 


\section{Past work}

- Sasidharan (2012)

- Detailed evaluation of the intensity normalization method used in this paper with different data samples is discussed in (Sasidharan, 2016).

- Lohani and Sasidharan (2013) - Preliminary report 


\section{Objectives}

- Minimize human intervention in data collection

- Propose a robust algorithm for automatic LiDAR data registration

- Algorithm must be less complex and easy to implement 


\section{Process Flow}

\section{Unregistered Point Clouds}

Intensity Normalization

Coarse Registration

Fine Registration 


\section{Terminologies}

- Iterative Closest Point Algorithm

- Intensity Normalization

- Intensity Augmented ICP 


\section{Iterative Closest Point (ICP) Algorithm}

- Classical solution for all types of 3D registration problems

- Proposed by Besl and McKay, (1992) and Chen and Medoni (1992) 


\section{ICP Steps}

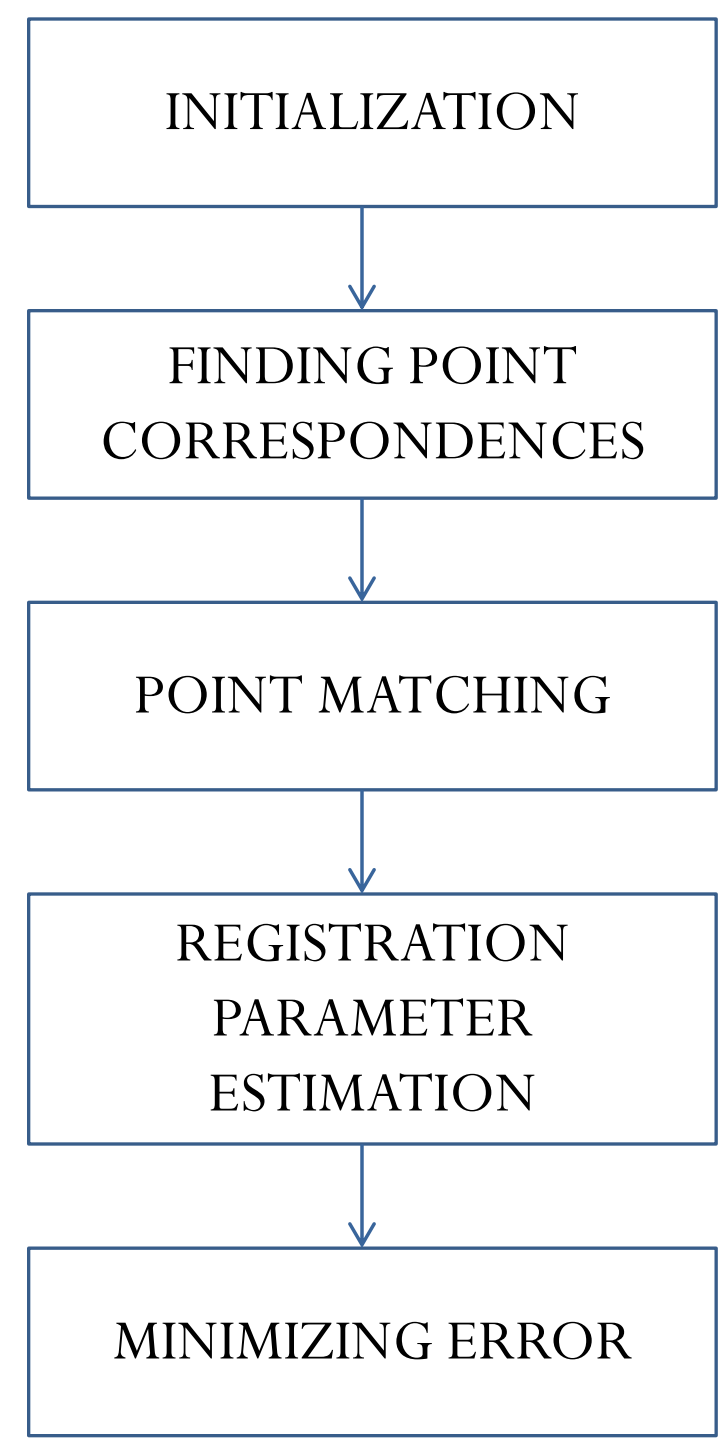




\section{ICP - Initialization}

- Initialization of Rotation Matrix and Translation Matrix

- Master and Slave point clouds separated by large distance

- Tendency of ICP to converge to local minimum 


\section{Finding Point Correspondences}

- Point to point correspondence between Slave and Master clouds based on Euclidian distance

- Any point search algorithm can be used

- Kd -Tree data structure for efficient searching (Masuda et al., 1996) 


\section{Point Matching}

- Point to point distance minimization (Besl and McKay, 1992)

- Point to plane minimization (Chen and Medoni, 1992) 


\section{Point to Point distance minimization}

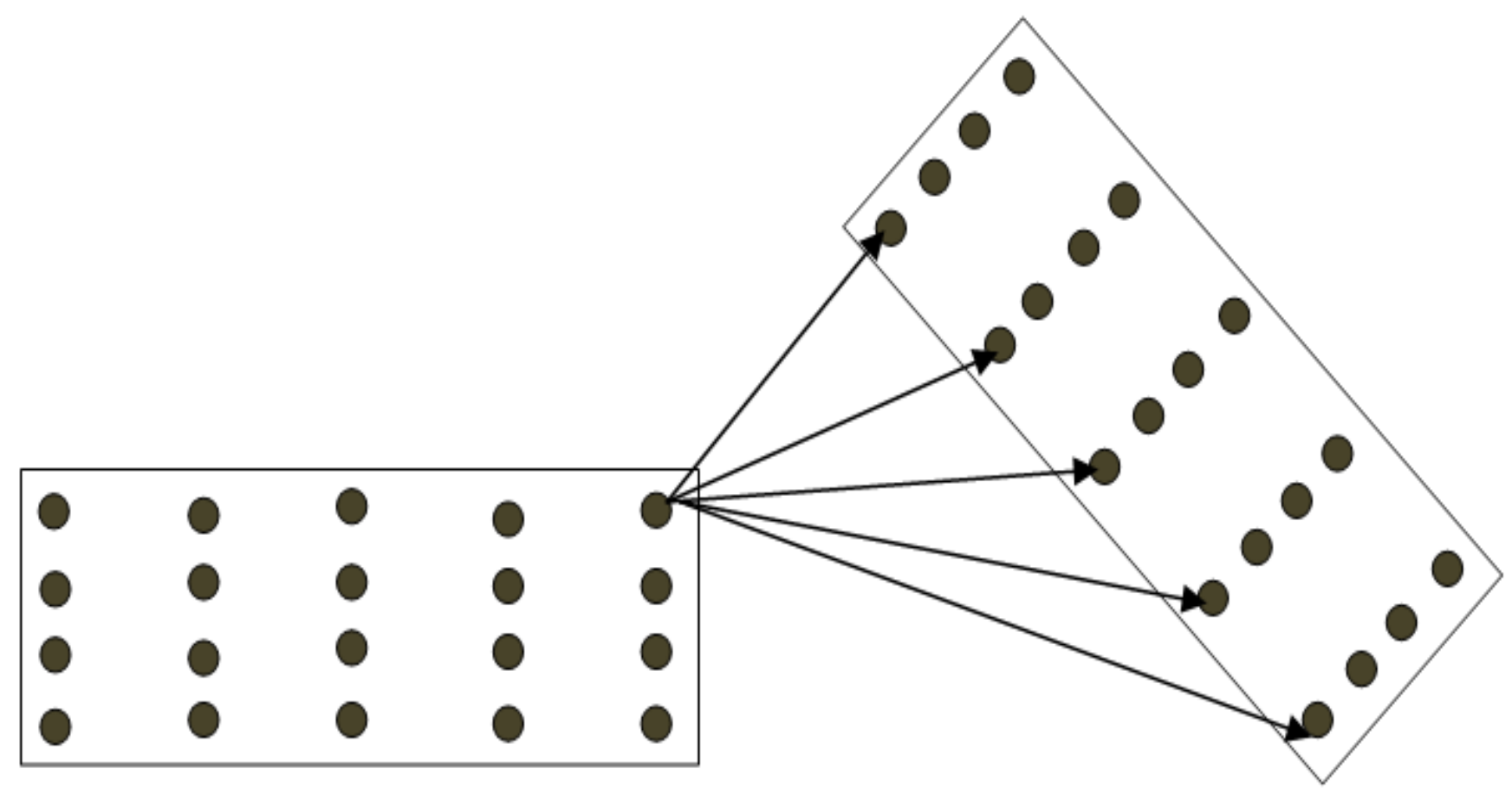

Slave Point Cloud

Master Point Cloud 


\section{Point to Plane distance minimization}

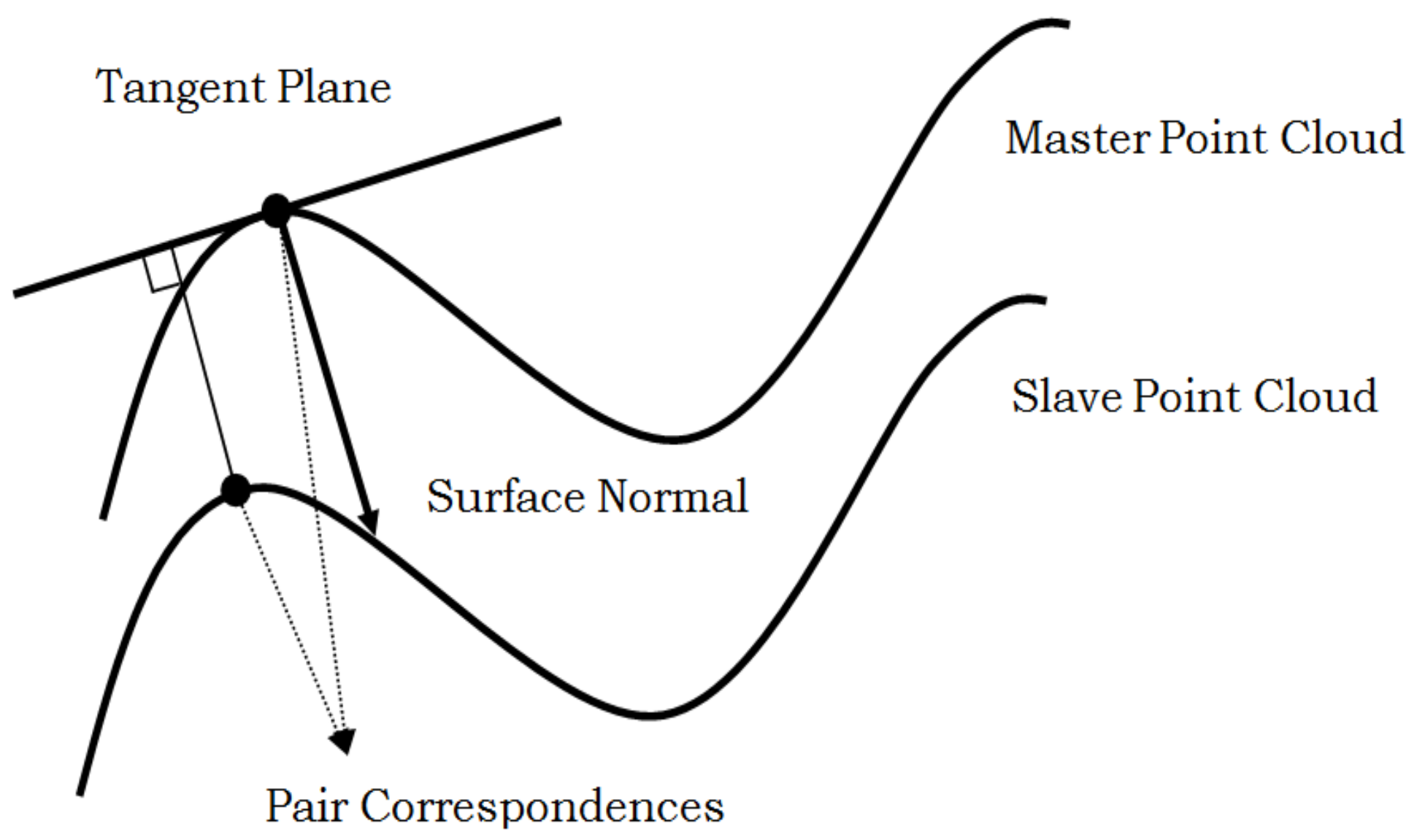




\section{Elimination of outliers}

- Wrongly matched points

- Presence of noise

- No $100 \%$ overlap

- Outlier elimination

- Based on Euclidean distance 


\section{Registration Parameter Estimation}

- At least 40-60 \% overlap for ICP to converge

- Calculate the covariance matrix between matched point clouds after subtracting the centroids

- Singular Value Decomposition of the Covariance Matrix 


\section{SVD Theorem}

- According to SVD theorem, any rectangular matrix A of size $\mathrm{N} \times \mathrm{P}$ can be decomposed as:

$$
A_{N \times P}=U_{N \times N} S_{N \times P} V_{P \times P}^{\top}
$$

- Where $U$ and $V$ are orthogonal

$$
\begin{aligned}
& U^{\top} U=I_{N \times N} \\
& V^{\top} V=I_{\text {PXP }}
\end{aligned}
$$




\section{Estimating Transformation Parameters using SVD}

- Proposed by Arun et al.,1987

$$
\begin{gathered}
\sum_{M D}=\frac{1}{N} \sum_{i=1}^{N}\left(M_{i}-\mu_{M}\right)\left(D_{i}-\mu_{D}\right)^{T} \\
\mathrm{R}(\omega, \varphi, \mathrm{K})=\mathrm{VSU}^{\top}
\end{gathered}
$$

$\mathrm{M}=$ Master cloud

$\mathrm{D}=$ Slave cloud

$\mathrm{R}=$ Rotation Matrix

$\mathrm{T}=$ Translation matrix

$\square_{\mathrm{M}}=$ Centroid of

Master

$\square_{\mathrm{D}}=$ Centroid of Slave

$$
T(x, y, z)=\square_{D}-R(\omega, \varphi, k) \square_{M}
$$




\section{Applying Transformation and Calculating RMS Error}

$D_{\square+1}=R(\omega, \varphi, k) * D_{\square}+T(x, y, z) \quad M=$ Master cloud

$\mathrm{D}=$ Slave cloud

$\mathrm{R}=$ Rotation Matrix

$\mathrm{T}=$ Translation matrix

$$
E_{R M S}=\sqrt{\frac{1}{N} \sum_{i}^{N}|| M_{i}-\left.\left(R D_{i}+T\right)\right|^{2}}
$$

$\square_{M}=$ Centroid of Master

$\square_{\mathrm{D}}=$ Centroid of Slave

$\mathrm{K}=$ Iteration Number

$\mathrm{N}=$ No. of

correspondences 


\section{Intensity Normalization}

- Intensity information collected is subjected to errors due to :

- Range difference

- Incidence angle difference

- Atmospheric losses

- Sensor sensitivity

- Surface geometry

- Temperature of the Electronic system

- Same materials have different intensity values 


\section{Intensity Range Correction}

- Range correction (Wagner et al., 2006)

$$
I_{\text {norm }}=I_{\text {raw }}\left(\frac{\boldsymbol{R}_{\text {act }}}{\boldsymbol{R}_{\text {ref }}}\right)^{n}
$$

- $n=2$ for homogeneous surfaces

- $I_{\text {norm }}$ is normalized intensity

- $I_{\text {raw }}$ is recorded intensity

- $R_{\text {act }}$ is actual distance between the laser instrument and the return

- $R_{\text {ref }}$ is a reference distance either determined by examining the distribution of $R_{a c t}$ from all returns of specified arbitrarily by users. 


\section{Intensity Incidence Angle Correction}

- Incidence angle correction (Gross et al., 2008) for planar points

$$
\boldsymbol{I}_{\text {norm }}=\boldsymbol{I}_{\text {raw }}\left(\frac{1}{\cos (i)}\right)
$$

- $I_{\text {raw }}$ is recorded intensity

- $I_{\text {norm }}$ is normalized intensity

- $i$ is the incidence angle 


\section{Intensity Correction formula}

$$
I_{\text {norm }}=I_{\text {raw }}\left(\frac{\boldsymbol{R}_{\text {act }}}{\boldsymbol{R}_{\text {ref }}}\right)^{2}\left(\frac{1}{\cos (i)}\right)
$$

- $I_{\text {norm }}$ is normalized intensity

- $I_{\text {raw }}$ is recorded intensity

- $R_{\text {act }}$ is actual distance between the laser instrument and the return

- $R_{\text {ref }}$ is a reference distance either determined by examining the distribution of $R_{\text {act }}$ from all returns of specified arbitrarily by users.

- $i$ is the incidence angle 


\section{Intensity Augmented ICP}

- Adding intensity information as $4^{\text {th }}$ dimension along with spatial coordinates ( $x, y, z$, Intensity)

- Intensity must be scaled by varying the value of $R_{\text {ref }}$

- Changing value of weight matrix

- Statistical score normalization can be employed 


\section{Methodology}

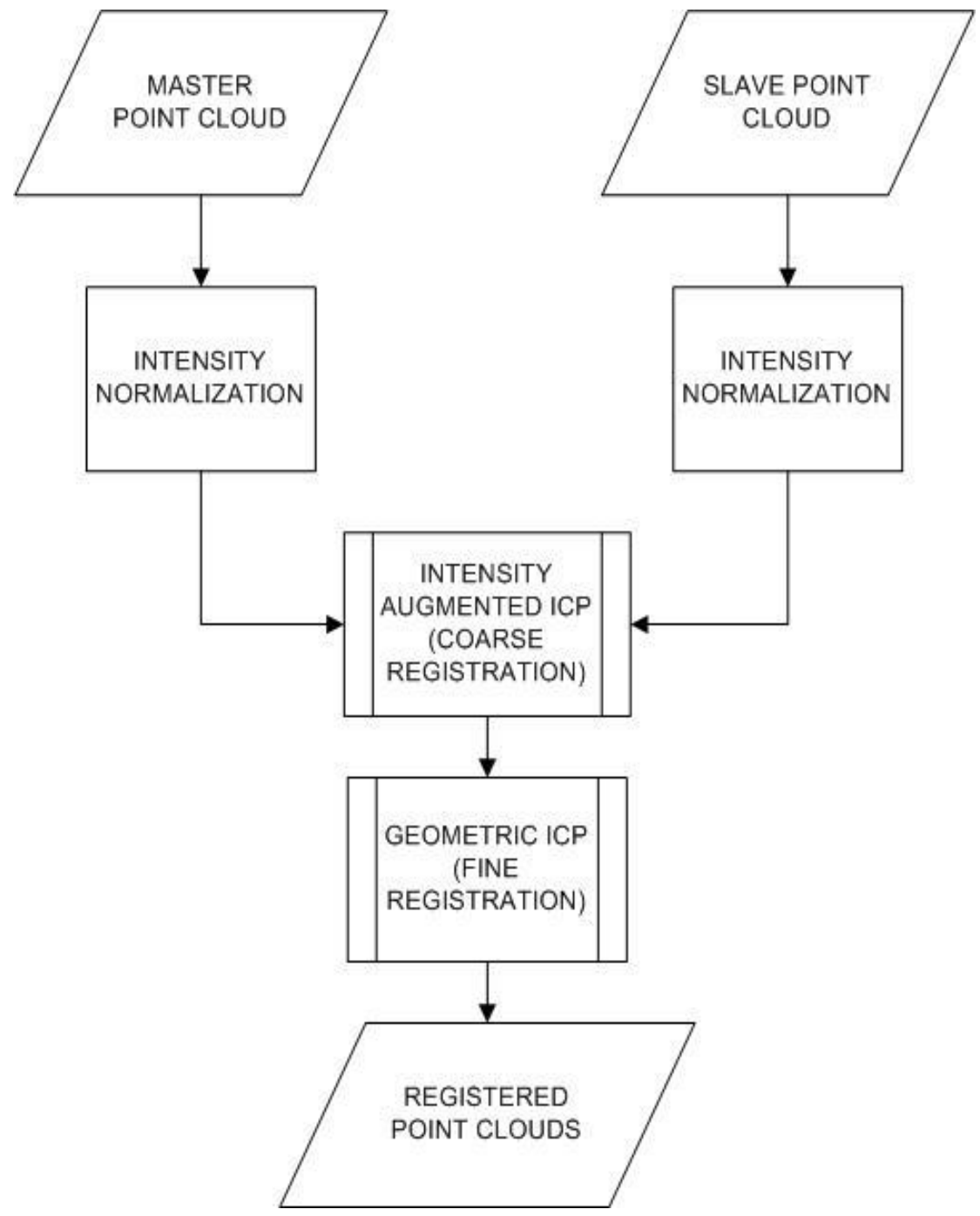




\section{Intensity Normalization}

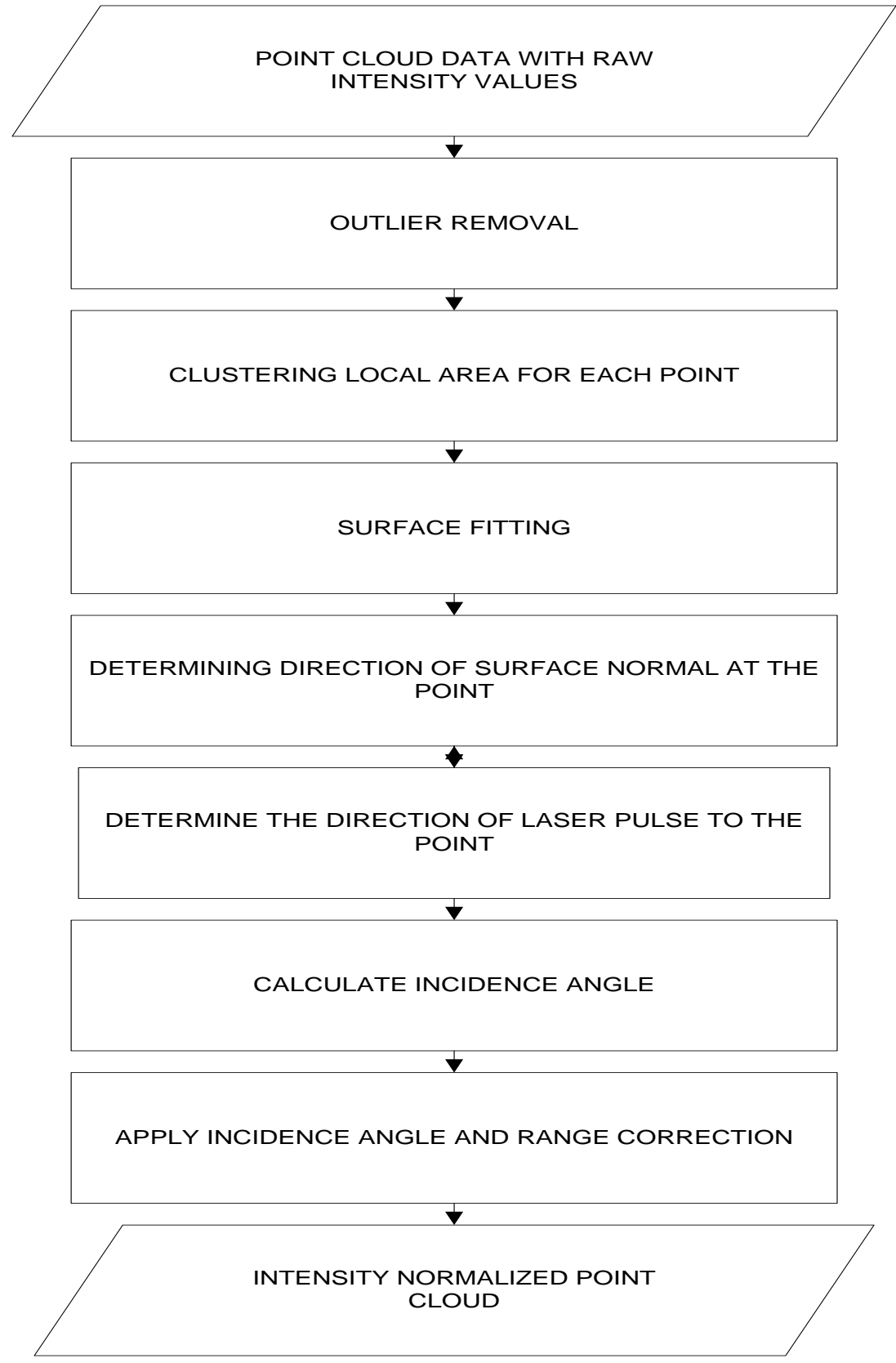




\section{Coarse Registration - Stage 1}

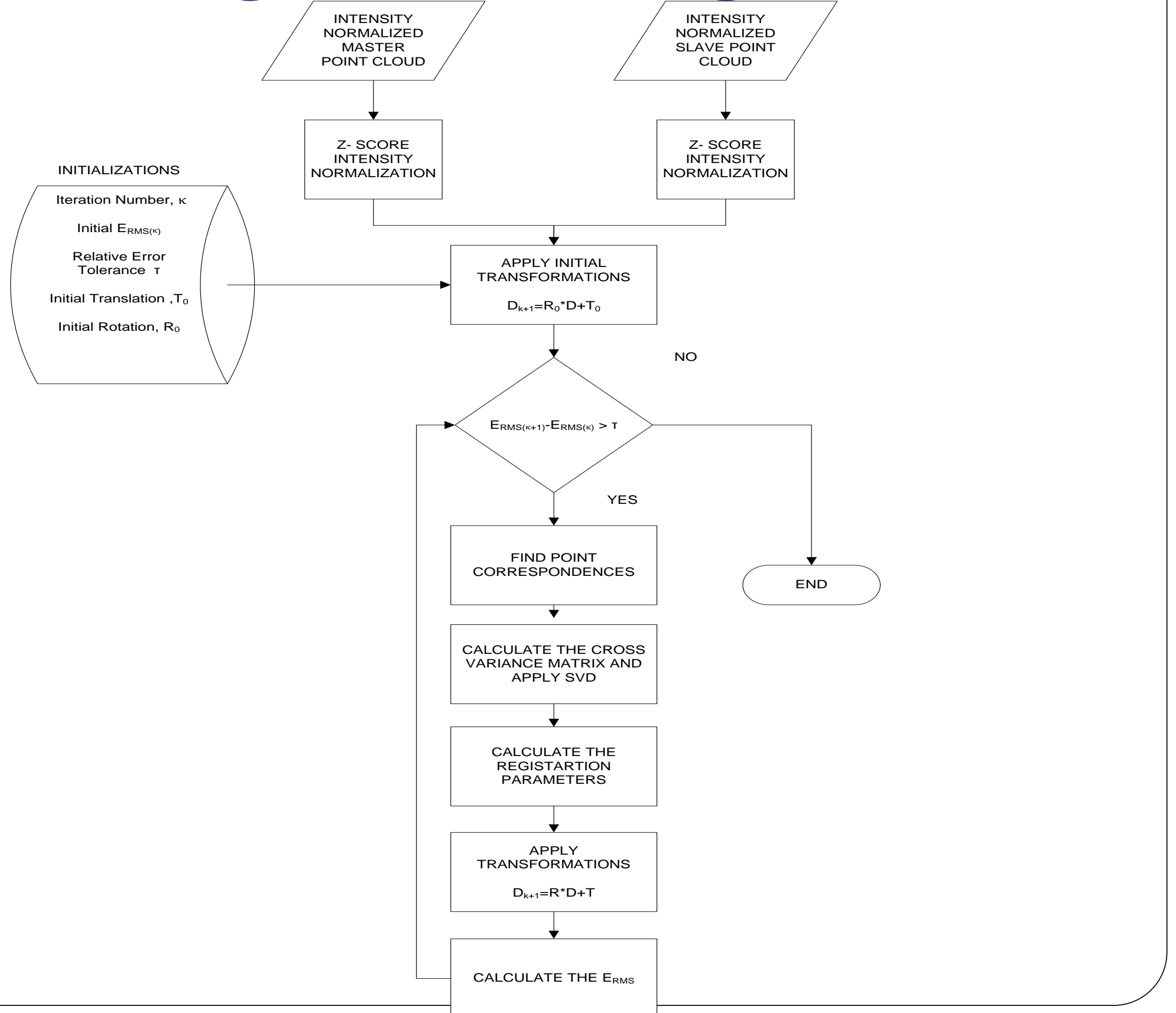




\section{Z score Normalization}

- Raw intensity captured by sensor is normally distributed (Hefford and Samson, 2009)

$$
I_{\text {znorm }}=\frac{I_{\text {norm }}-\mu_{I_{\text {norm }}}}{\sigma_{I_{\text {norm }}}}
$$

$\mathrm{I}_{\text {znorm }}=\mathrm{Z}$ score Normalized Intensity

$I_{\text {norm }}=$ Normalized Intensity

$\square_{\text {Inorm }}=$ Mean of Normalized Intensity

$\square_{\text {Inorm }}=$ Standard Deviation of Normalized Intensity

- After Z-score normalization, the intensity values have a mean of zero and unit standard deviation. (Jain et al., 2005) 


\section{Fine Registration - Stage 2}

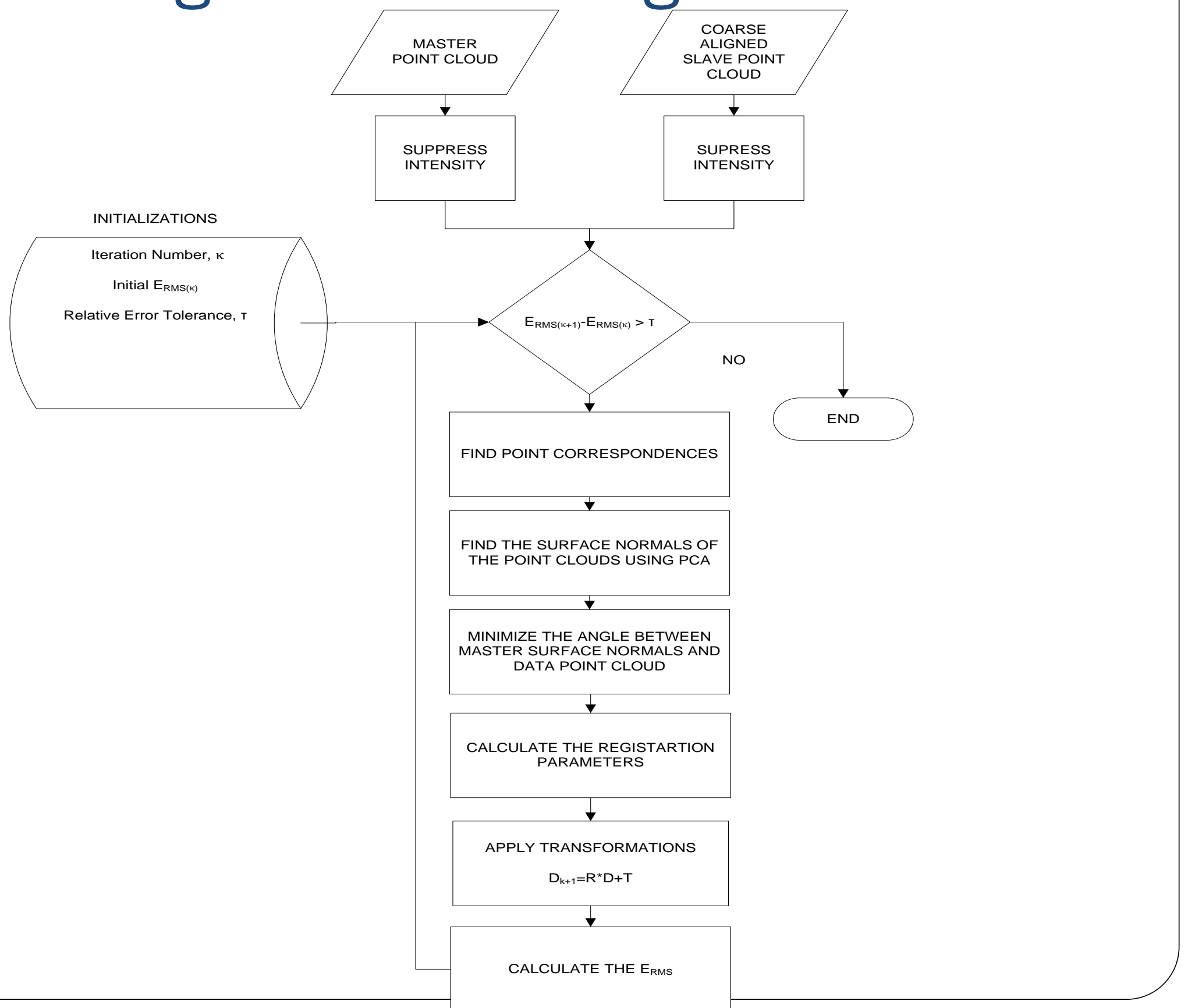




\section{Results - Intensity Normalization}

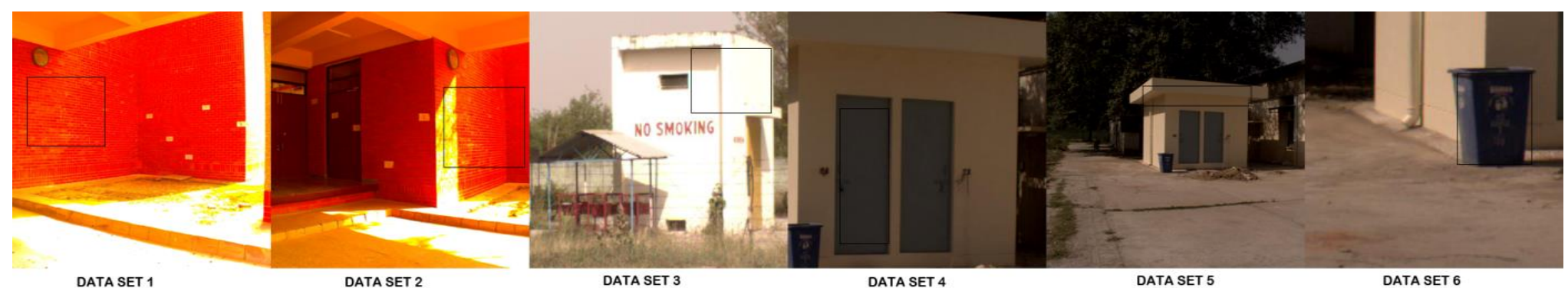

\begin{tabular}{|c|c|c|c|c|c|c|}
\hline Data Set No & Material & Scan No & Raw Mean & Raw SD & Normalized Mean & Normalized SD \\
\hline \multirow{2}{*}{ Set 1 } & \multirow{2}{*}{ Brick wall } & Scan 1 & 3290 & 622 & 44 & 8 \\
\cline { 3 - 7 } & & Scan 2 & 4365 & 778 & 53 & 9 \\
\hline \multirow{2}{*}{ Set 2 } & \multirow{2}{*}{ Brick wall } & Scan 1 & 4365 & 778 & 53 & 9 \\
\cline { 3 - 7 } & & Scan 2 & 1728 & 361 & 67 & 14 \\
\hline \multirow{2}{*}{ Set 3 } & \multirow{2}{*}{ Concrete } & Scan 1 & 418 & 192 & 104 & 48 \\
\cline { 3 - 7 } & Wall & Scan 2 & 1385 & 505 & 147 & 53 \\
\hline \multirow{2}{*}{ Set 4 } & \multirow{2}{*}{ Iron Door } & Scan 1 & 1900 & 284 & 34 & 4 \\
\cline { 3 - 7 } & \multirow{2}{*}{ Concrete } & Scan 2 & 1680 & 206 & 30 & 60 \\
\cline { 3 - 7 } & Wall & Scan 1 & 406 & 200 & 120 & 68 \\
\hline \multirow{2}{*}{ Set 6 } & Plastic & Scan 2 & 1070 & 603 & 136 & 7.5 \\
\cline { 3 - 7 } & Object & Scan 2 & 1805 & 553 & 36 & 7.9 \\
\hline
\end{tabular}



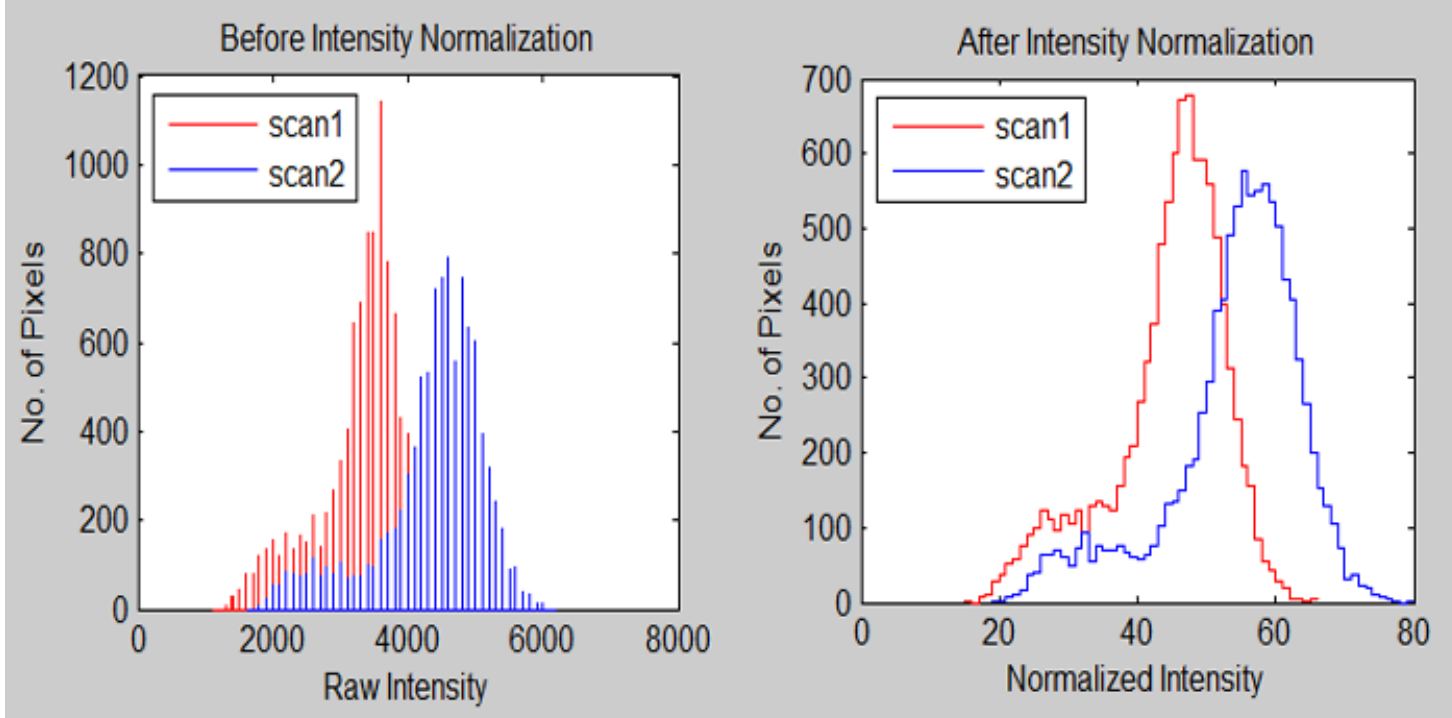

Histograms of Data Set 1.

Number of points in scan $1=$ 30293 and scan $2=30247$
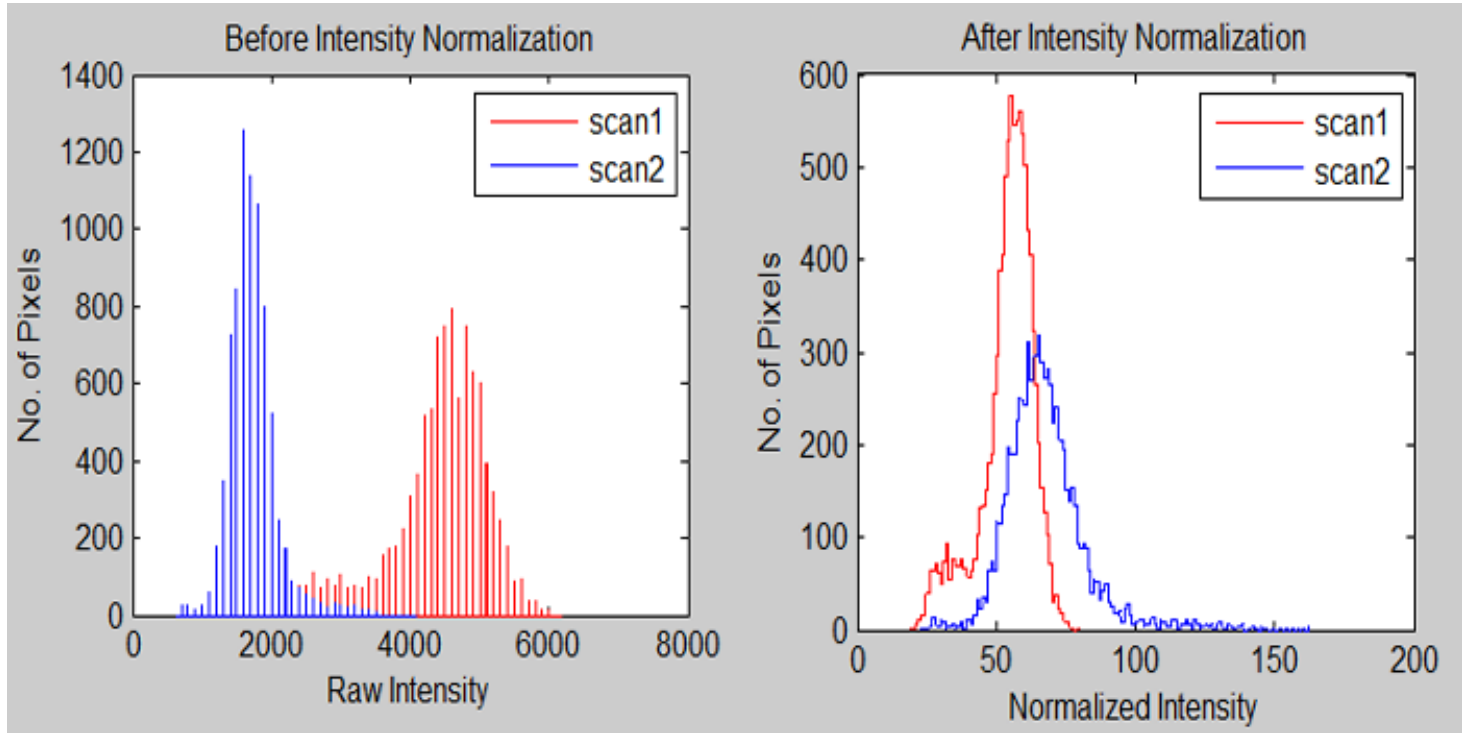

Histograms of Data Set 2.

Number of points in scan $1=$ 30247 and scan $2=24625$ 

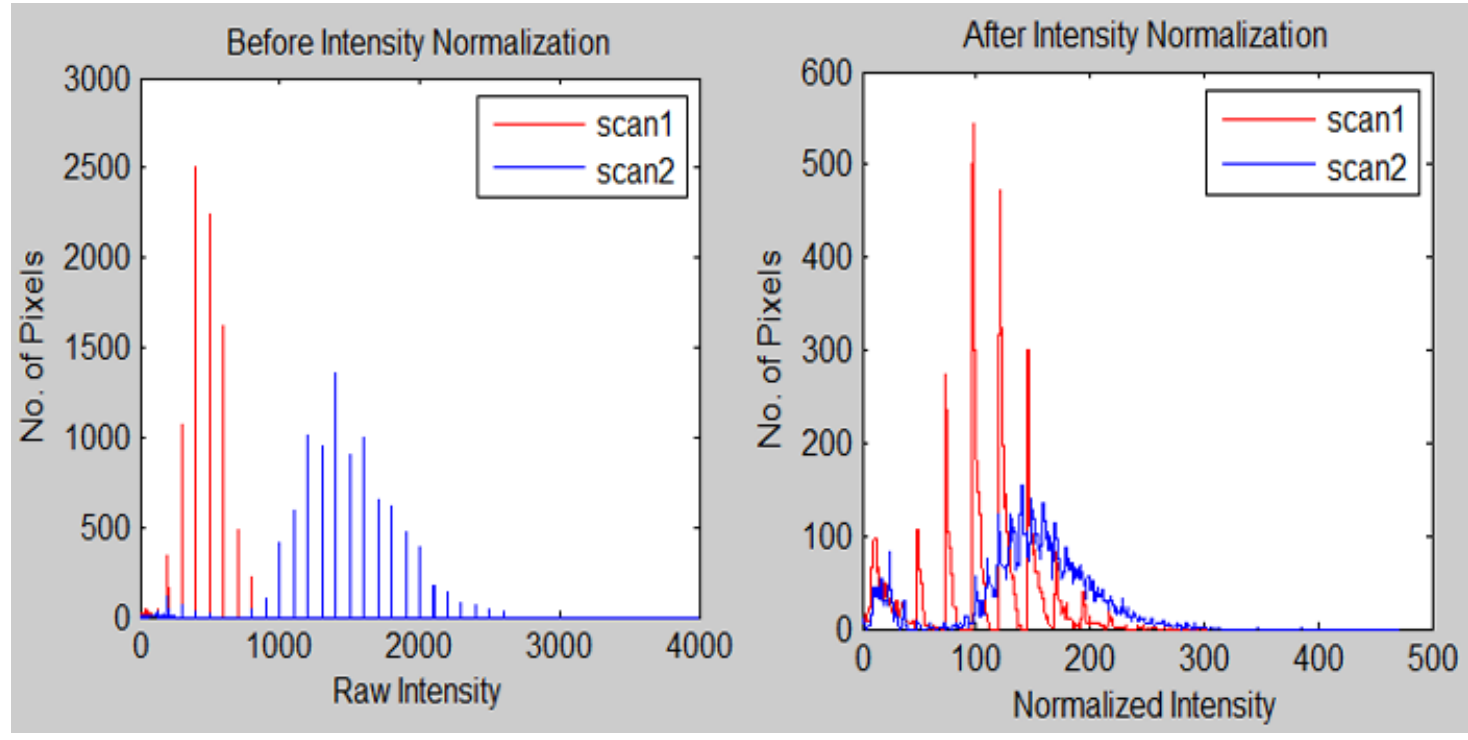

Histograms of Data Set 3.

Number of points in scan $1=$ 7368 and scan $2=4328$

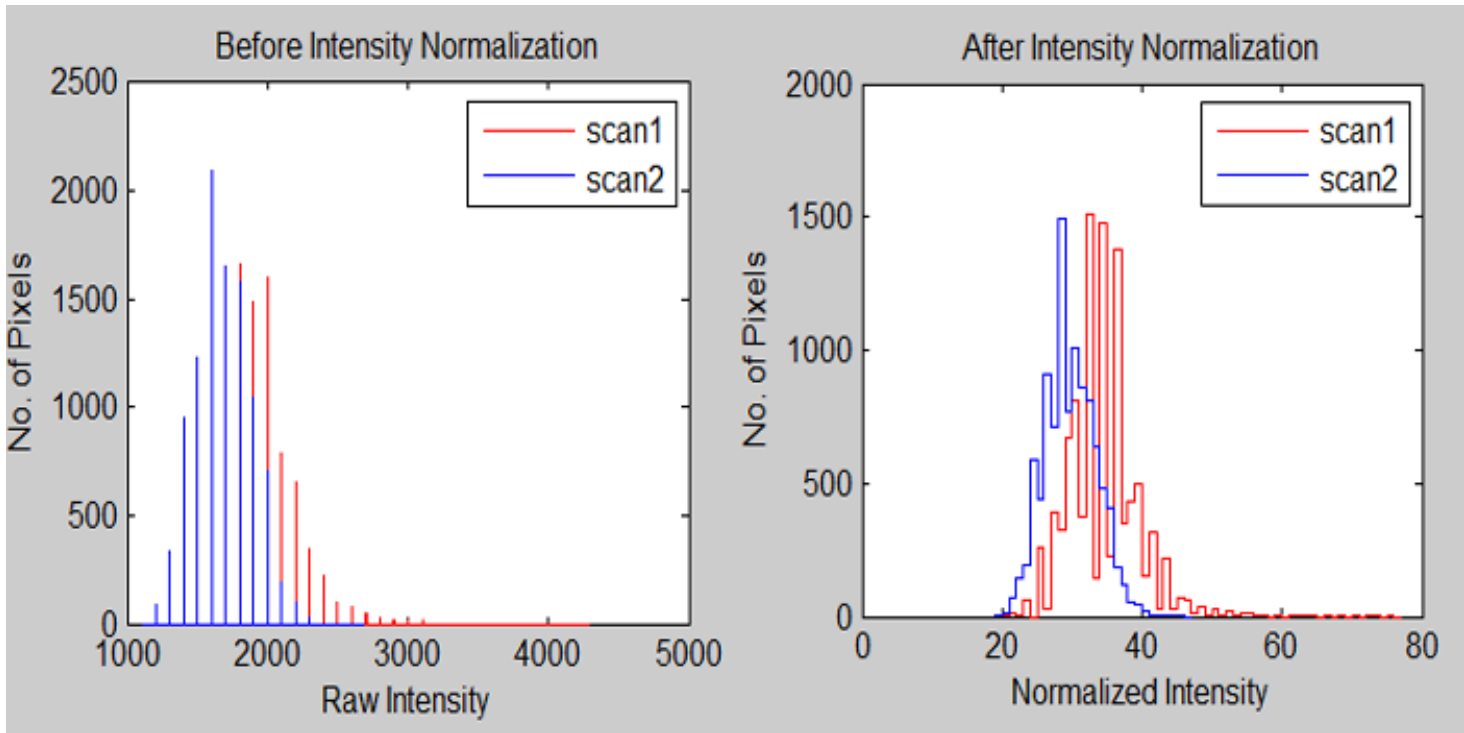

Histograms of Data Set 4.

Number of points in scan $1=$ 7128 and $\operatorname{scan} 2=6205$ 

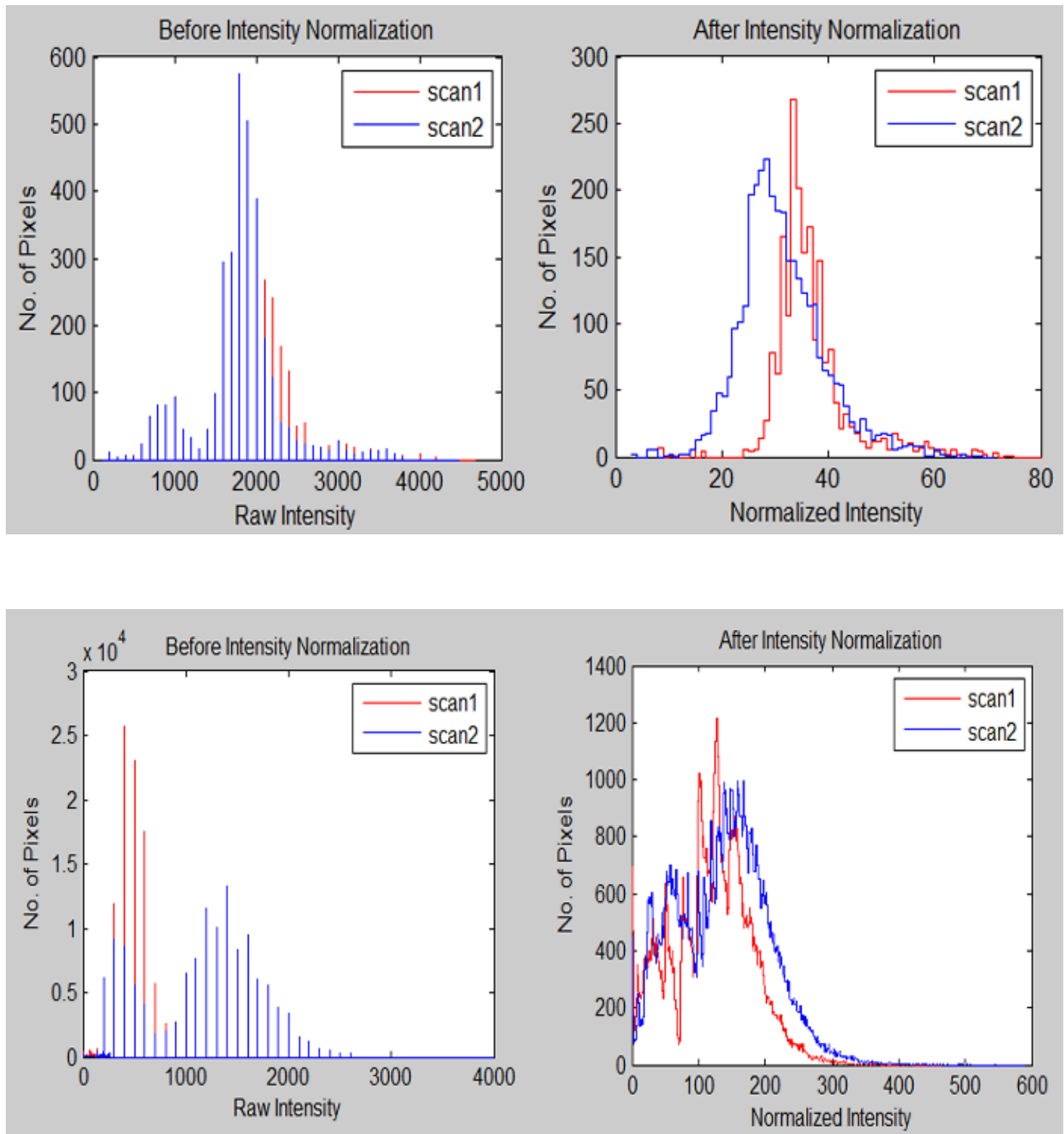

Histograms of Data Set 5.

Number of points in scan $1=$ 1976 and scan $2=998$
Histograms of Data Set 6.

Number of points in scan $1=$ 11976 and scan $2=11312$ 


\section{Testing the Normalization Results}

$$
\begin{aligned}
& \boldsymbol{\rho}= \frac{\boldsymbol{\mu}_{\boldsymbol{i}}-\boldsymbol{\mu}_{\boldsymbol{j}}}{\boldsymbol{\sigma}_{\boldsymbol{i}}+\boldsymbol{\sigma}_{\boldsymbol{j}}} \\
& \rho \text { is the distance co-efficient for the distribution } \\
& \mu \text { is the mean of the intensity values } \\
& \sigma \text { is the standard deviation of intensity values } \\
& \text { with } i \text { and } j \text { are scan numbers }
\end{aligned}
$$

\begin{tabular}{|c|c|c|c|c|c|c|}
\hline Data Set & Set 1 & Set 2 & Set 3 & Set 4 & Set 5 & Set 6 \\
\hline Raw & 0.77 & 2.31 & 1.39 & 0.45 & 0.83 & 0.39 \\
\hline Normalized & 0.53 & 0.61 & 0.43 & 0.44 & 0.13 & 0.32 \\
\hline
\end{tabular}




\section{Conventional ICP Vs IAICP}

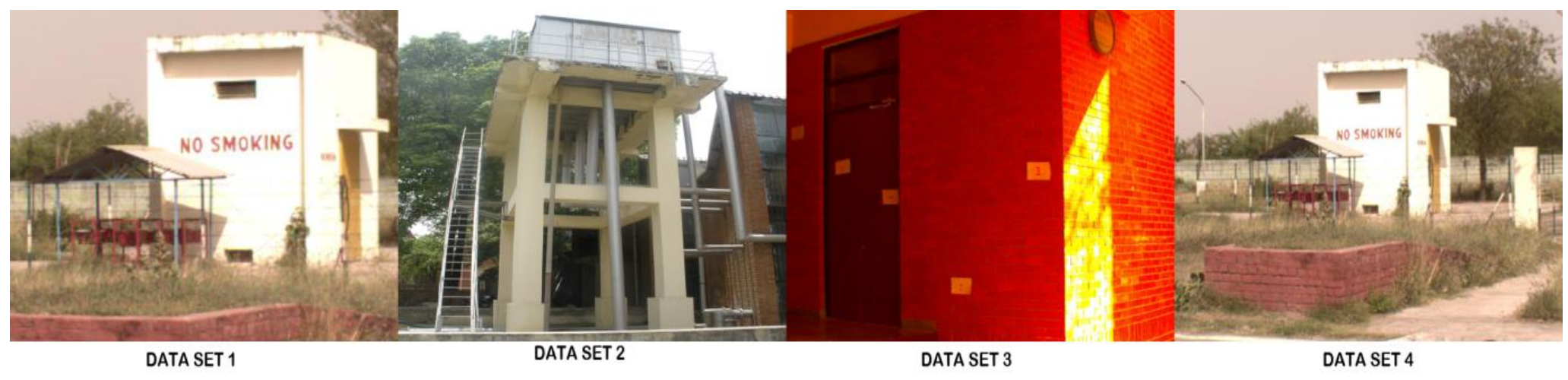

- Only coarse stage

- Intensity Normalization performed 
Data Set - 1

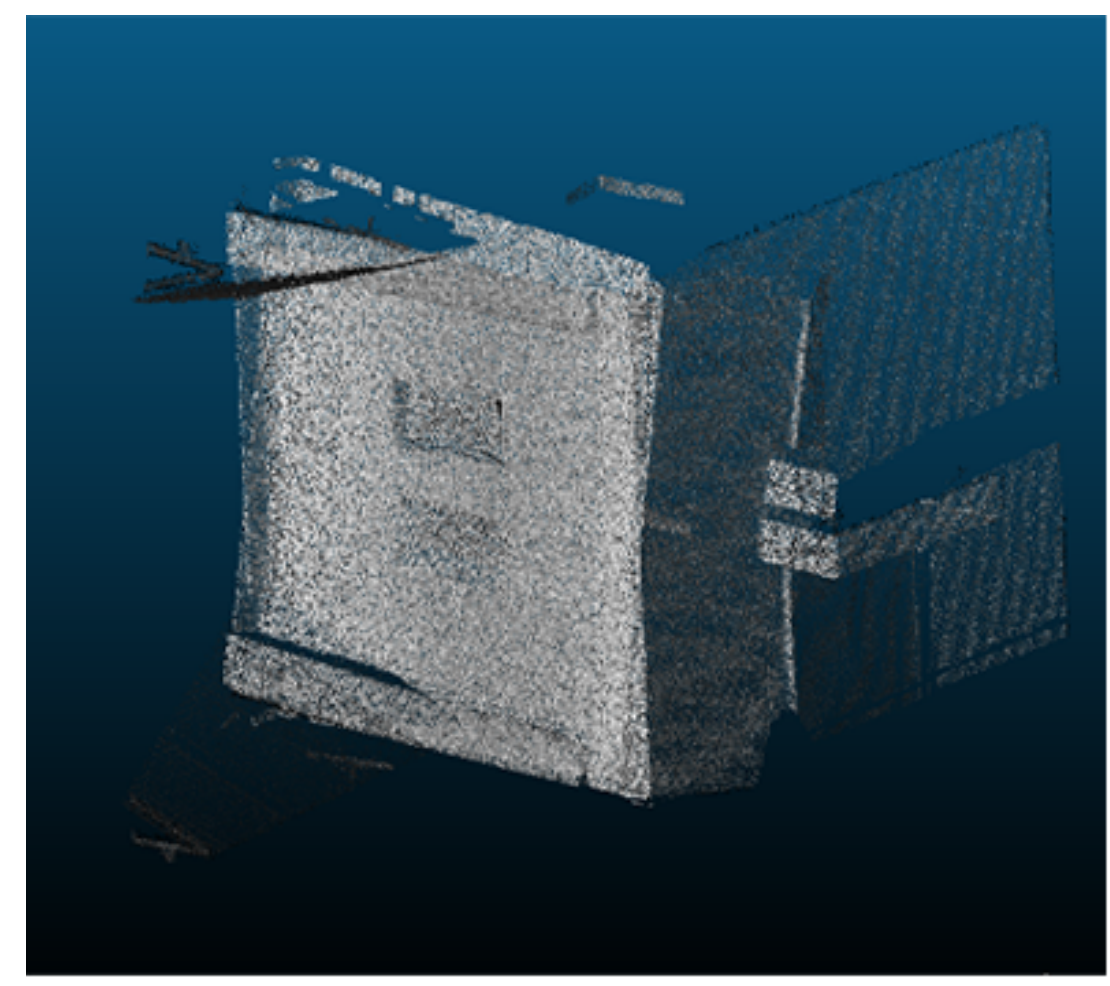

Geometric ICP

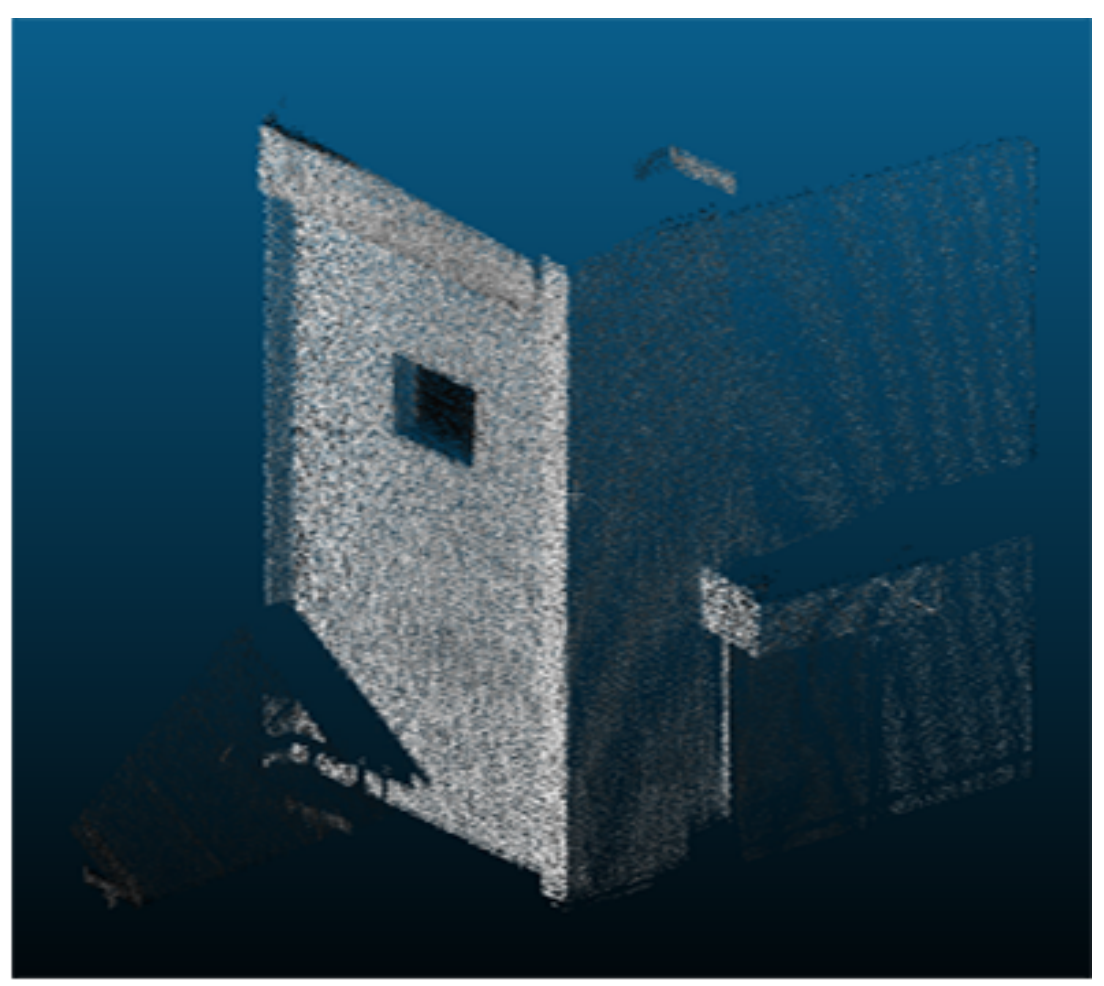

Intensity Augmented ICP 


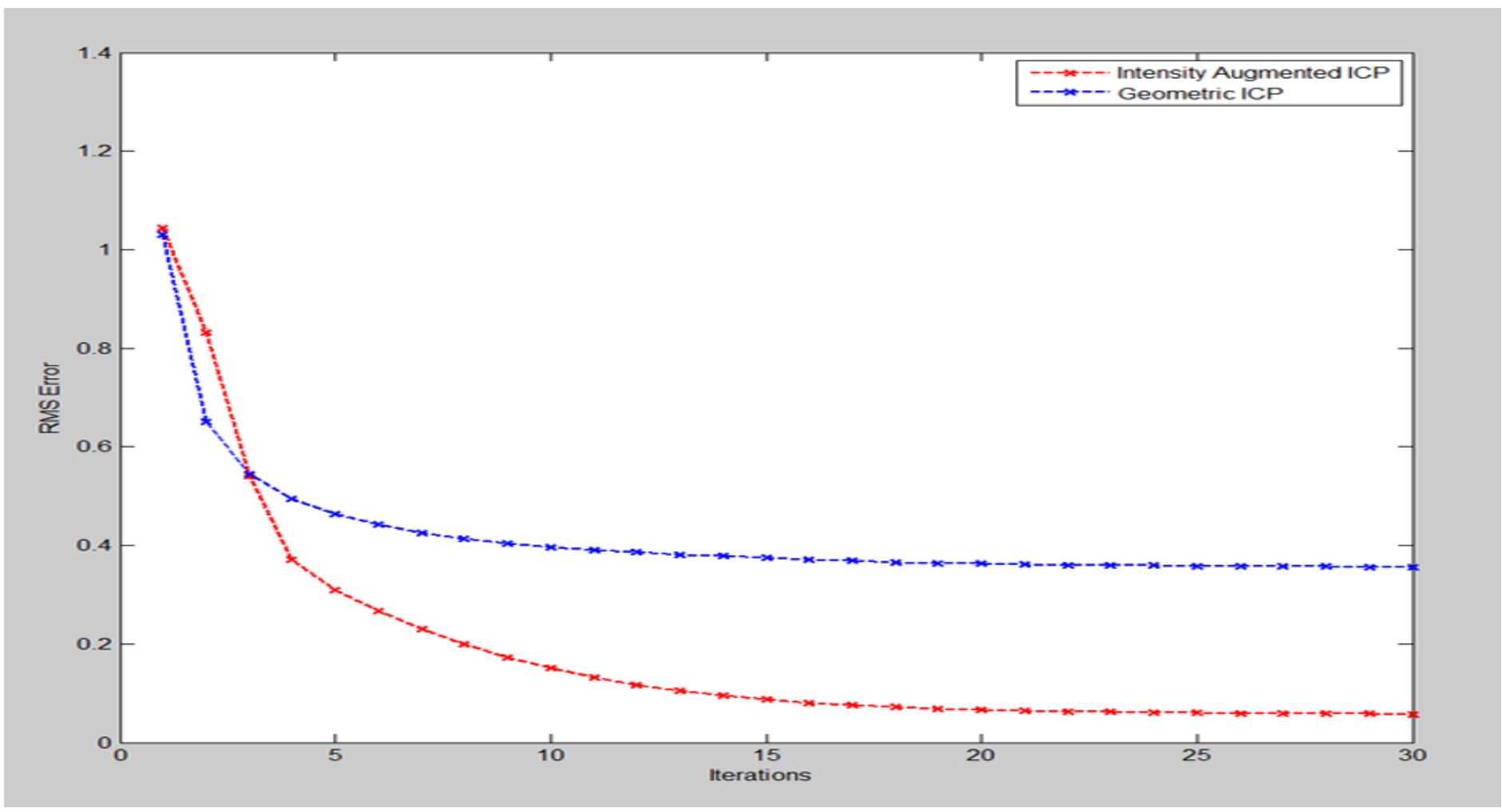

Method

RMS Error
Geometric ICP

$0.3563 \mathrm{~m}$
Intensity Augmented ICP

$0.0577 \mathrm{~m}$ 
Data Set - 2

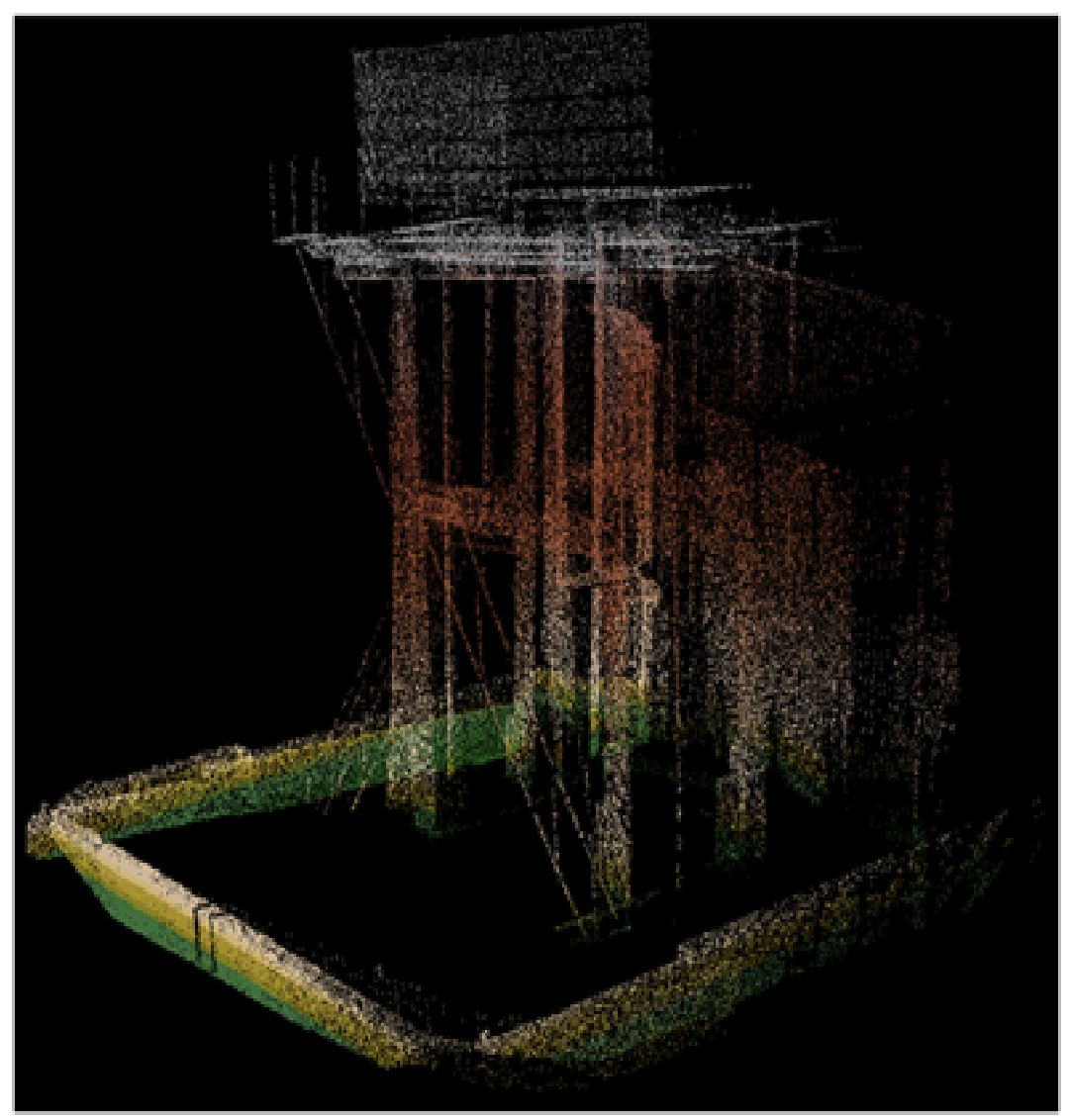

Geometric ICP

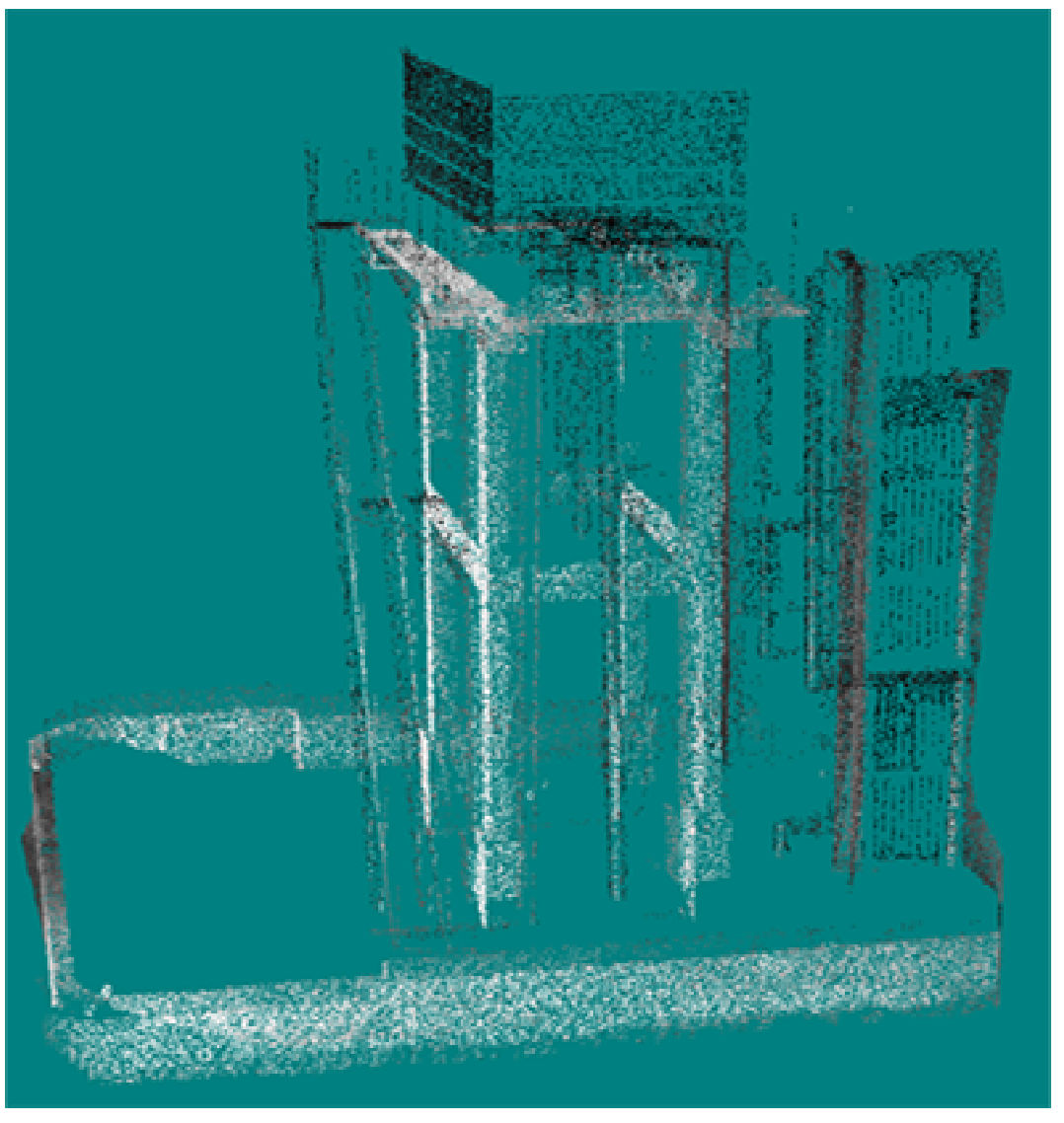

Intensity Augmented ICP 


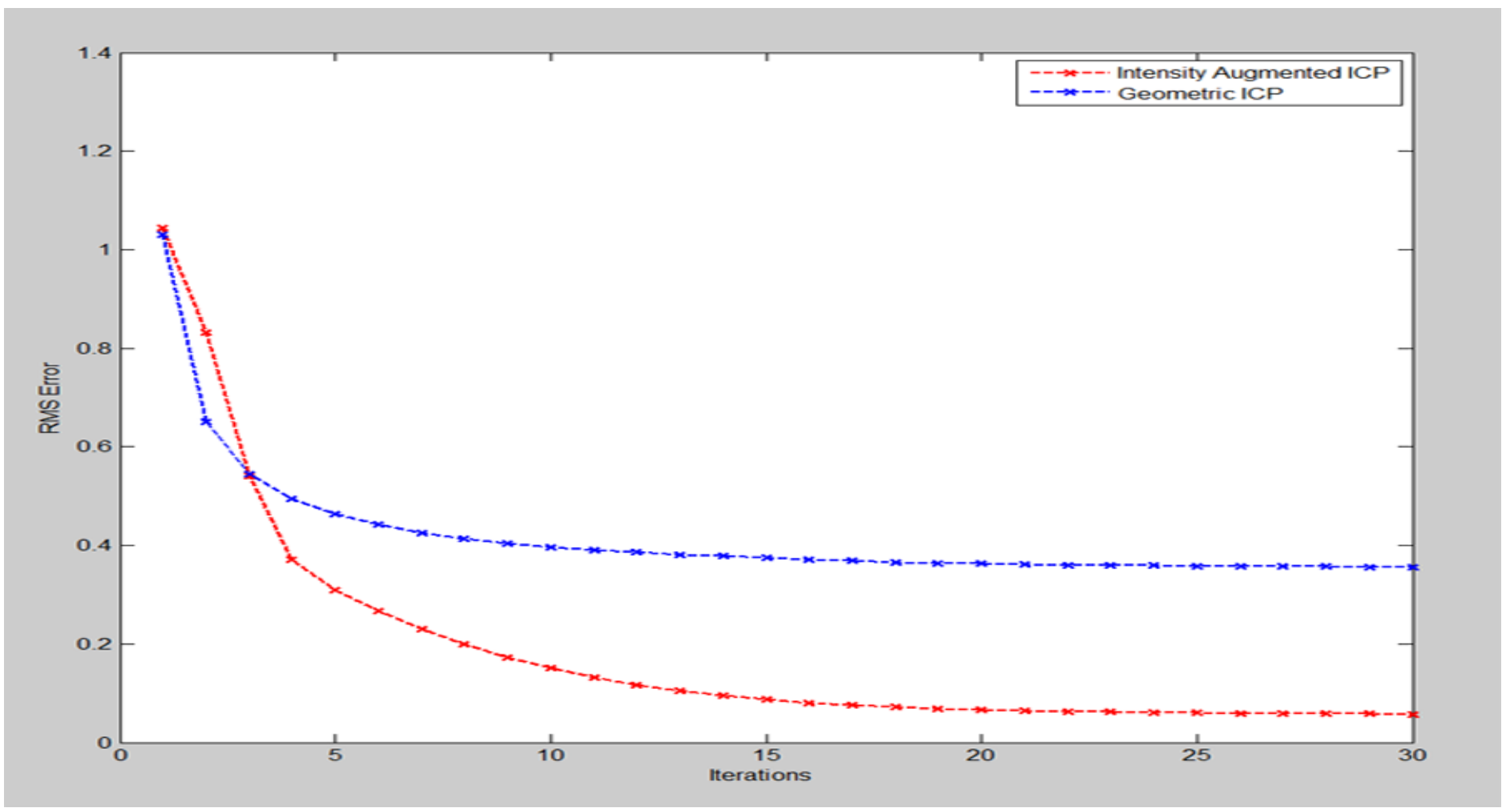

Method

RMS Error
Geometric ICP

$0.3563 \mathrm{~m}$
Intensity Augmented ICP

$0.0577 \mathrm{~m}$ 
Data Set - 3

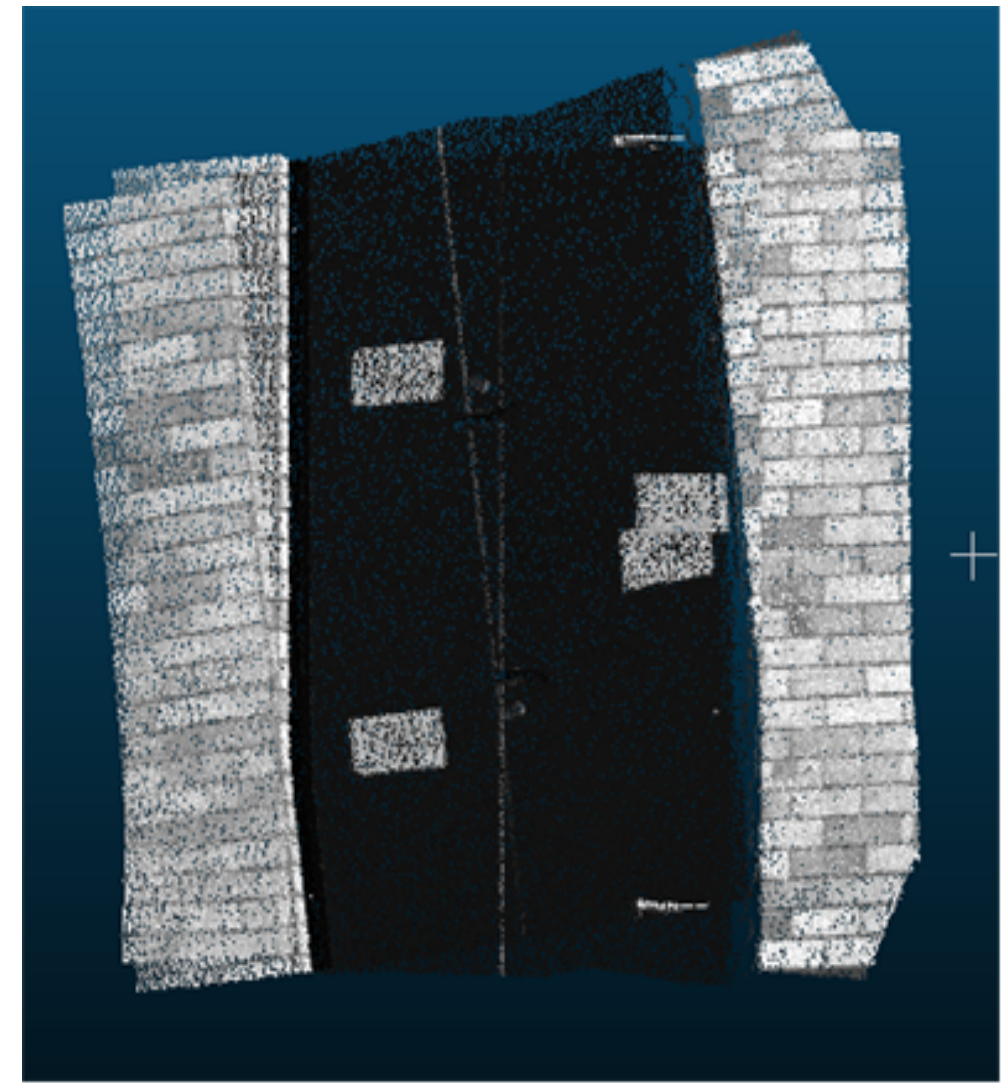

Geometric ICP

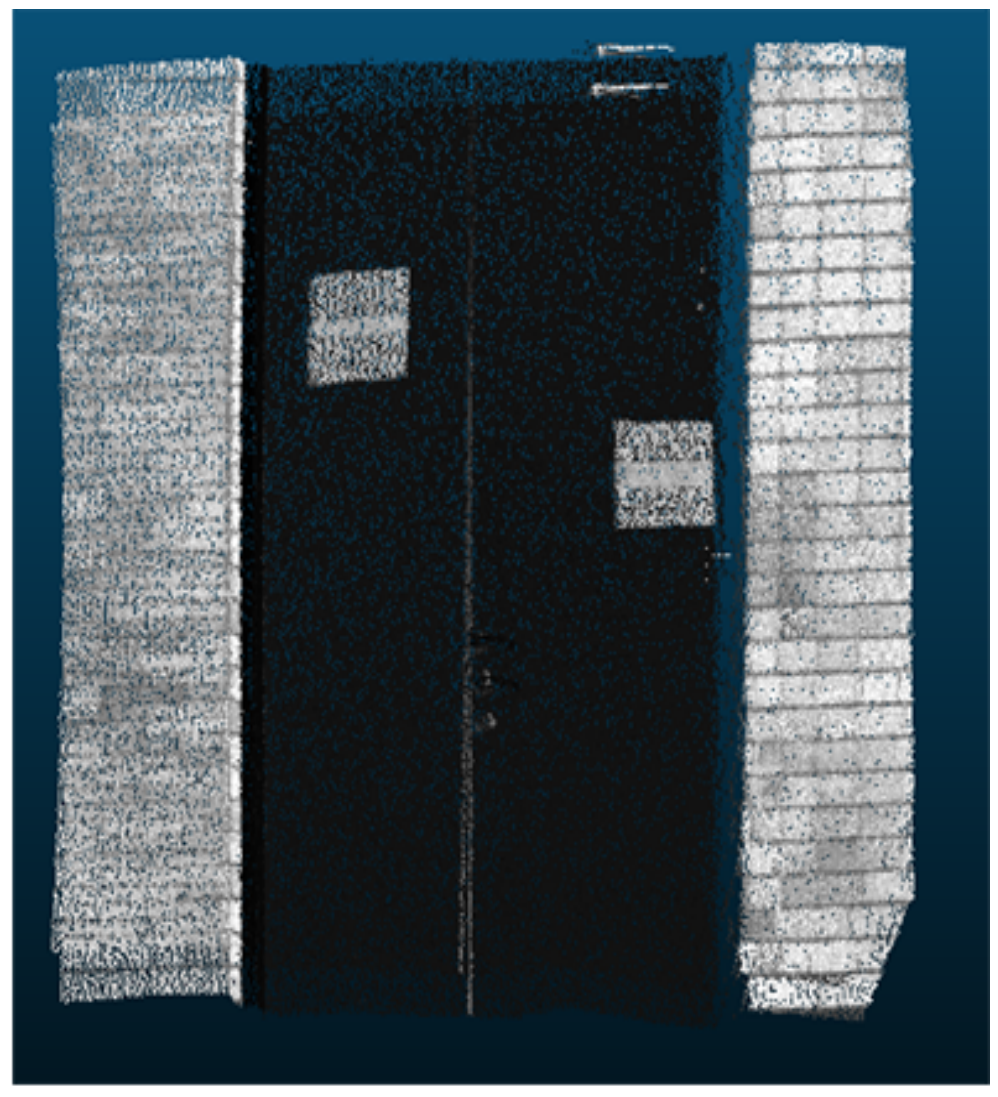

Intensity Augmented ICP 


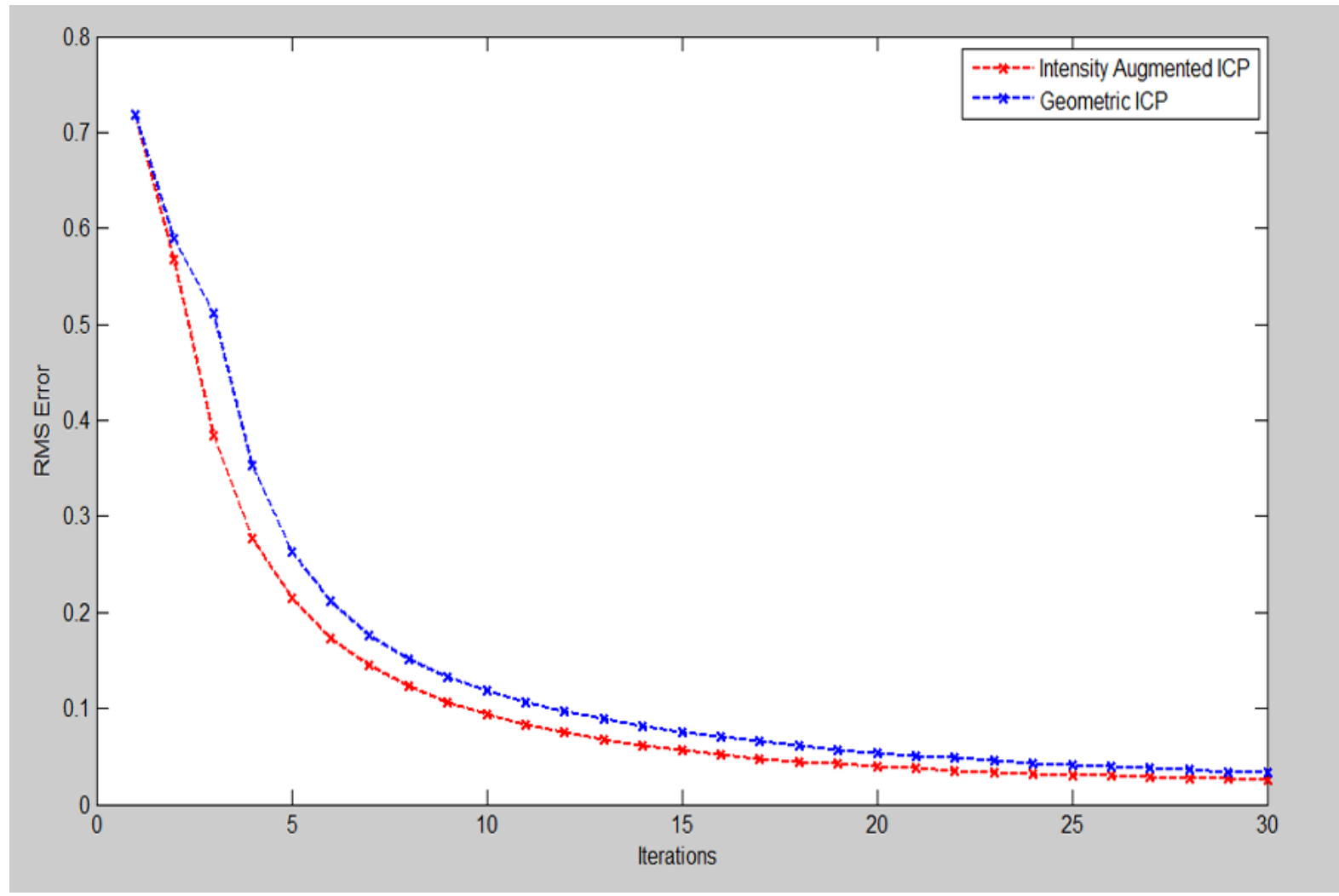

\begin{tabular}{|c|c|c|}
\hline Method & Geometric ICP & Intensity Augmented ICP \\
\hline RMS Error & $0.0326 \mathrm{~m}$ & $0.0261 \mathrm{~m}$ \\
\hline
\end{tabular}




\section{Accuracy of the Proposed Algorithm}

$$
E_{R M S}=\sqrt{\frac{1}{N} \sum_{i}^{N}|| M_{i}-\left(R D_{i}+T\right)||^{2}}
$$

M - Master point cloud

D- Slave point cloud

R- Rotation matrix

T- Translation matrix

N- Number of correspondences

RMS - Normalized root mean square error 


\section{Accuracy - Data Set 1}

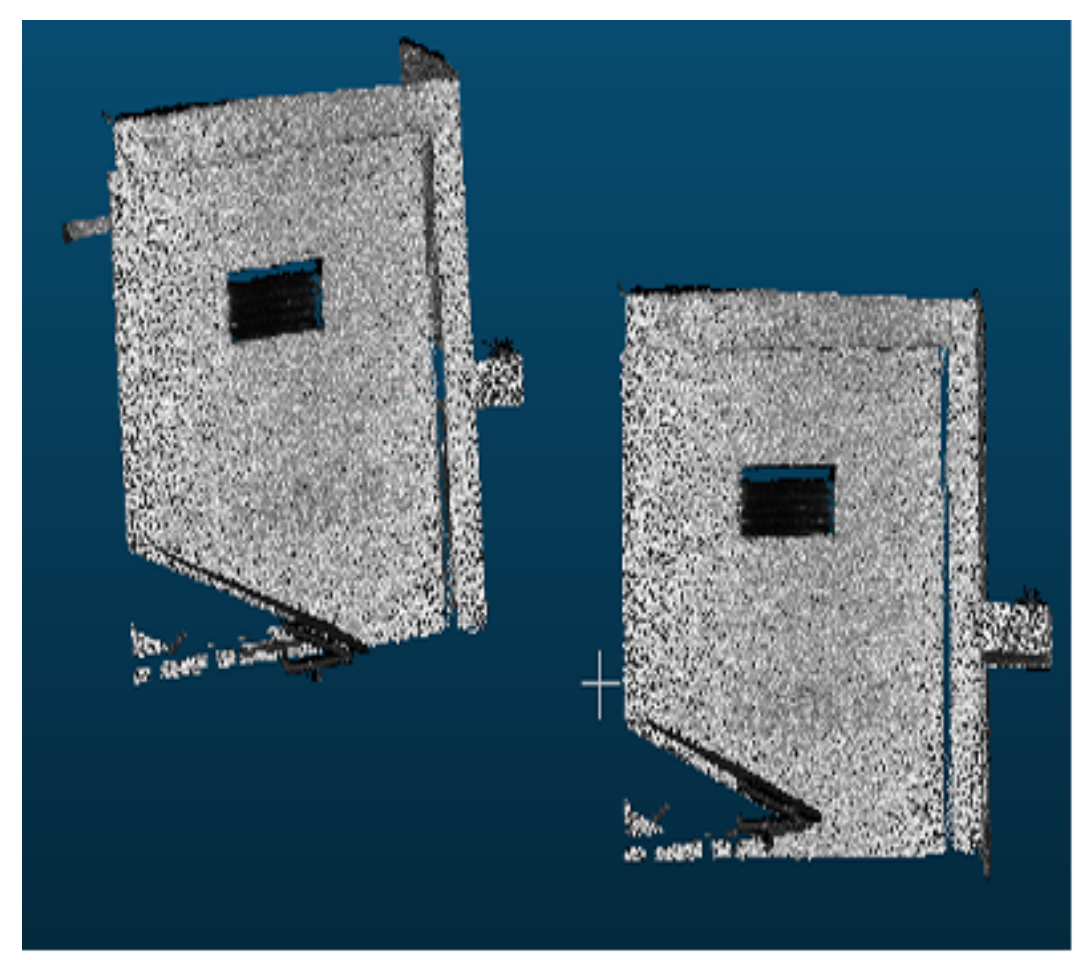

Before Registration

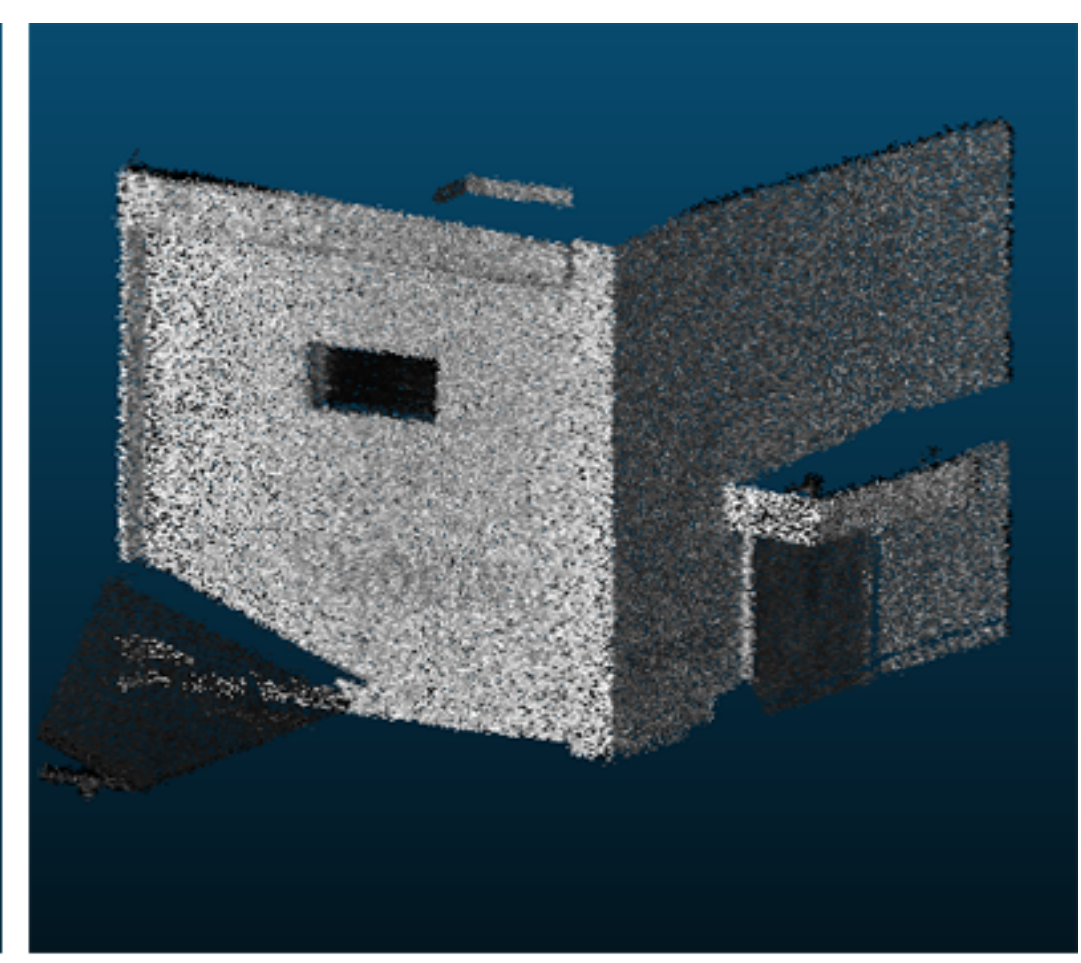

After Registration 


\section{Accuracy - Data Set 1}

\begin{tabular}{|c|c|c|c|}
\hline Parameter & True Value & Estimated Value & Error \\
\hline $\mathrm{Tx}$ & $0.5 \mathrm{~m}$ & $0.53 \mathrm{~m}$ & $-0.03 \mathrm{~m}$ \\
\hline $\mathrm{Ty}$ & $-0.3 \mathrm{~m}$ & $-0.25 \mathrm{~m}$ & $-0.05 \mathrm{~m}$ \\
\hline $\mathrm{Tz}$ & $0.2 \mathrm{~m}$ & $0.18 \mathrm{~m}$ & $0.02 \mathrm{~m}$ \\
\hline $\mathrm{Rx}$ & $0.30 \mathrm{rad}$ & $0.2998 \mathrm{rad}$ & $0.0002 \mathrm{rad}$ \\
\hline $\mathrm{Ry}$ & $-0.20 \mathrm{rad}$ & $-0.1997 \mathrm{rad}$ & $-0.0003 \mathrm{rad}$ \\
\hline $\mathrm{Rz}$ & $0.05 \mathrm{rad}$ & $0.0540 \mathrm{rad}$ & $-0.004 \mathrm{rad}$ \\
\hline Translation Error, || $\mathbf{E}_{\mathrm{t}}||$ & \multicolumn{2}{|c|}{$0.0612 \mathrm{~m}$} \\
\hline \multicolumn{2}{|c|}{$0.0040 \mathrm{rad}$} \\
\hline
\end{tabular}

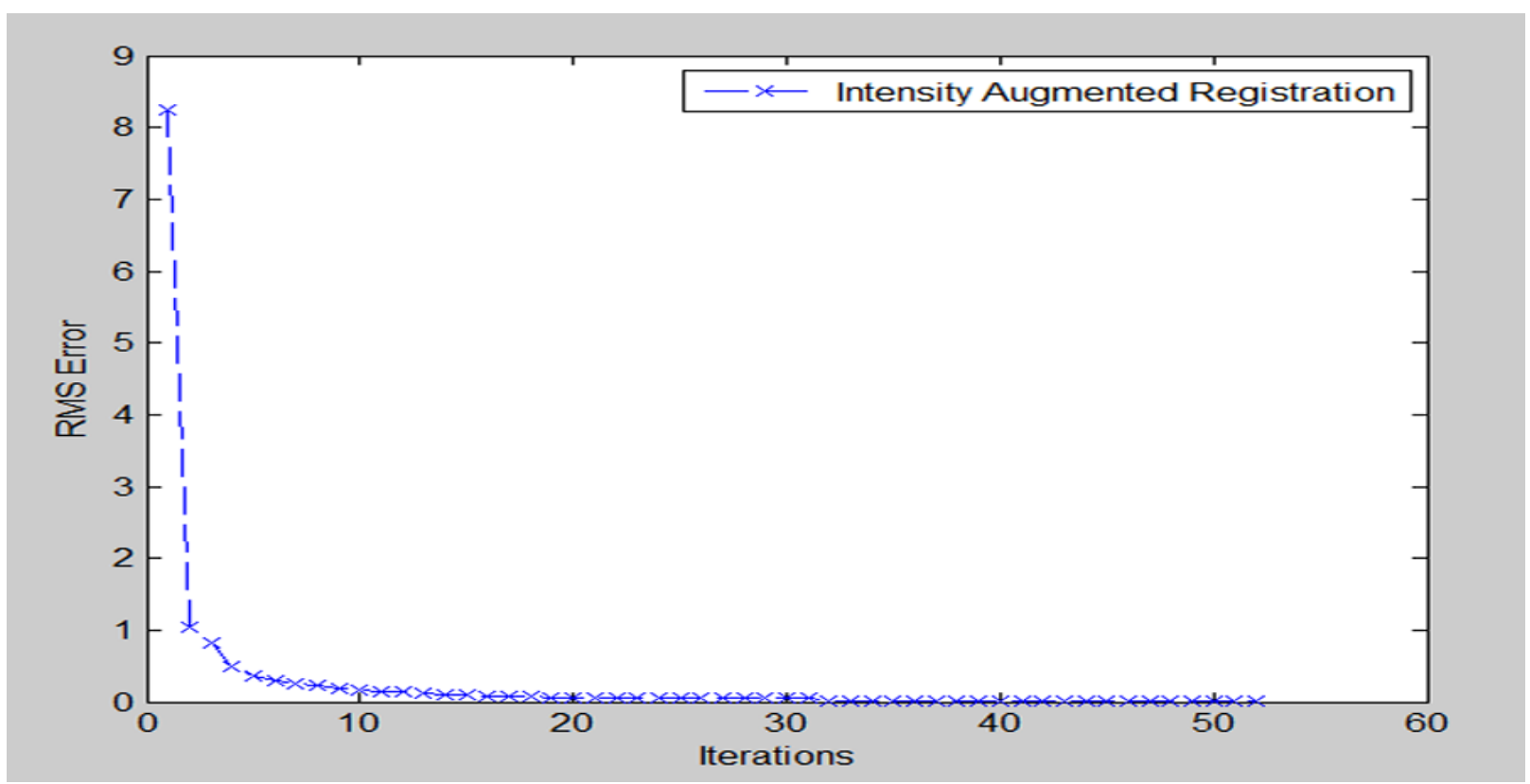




\section{Accuracy - Data Set 2}

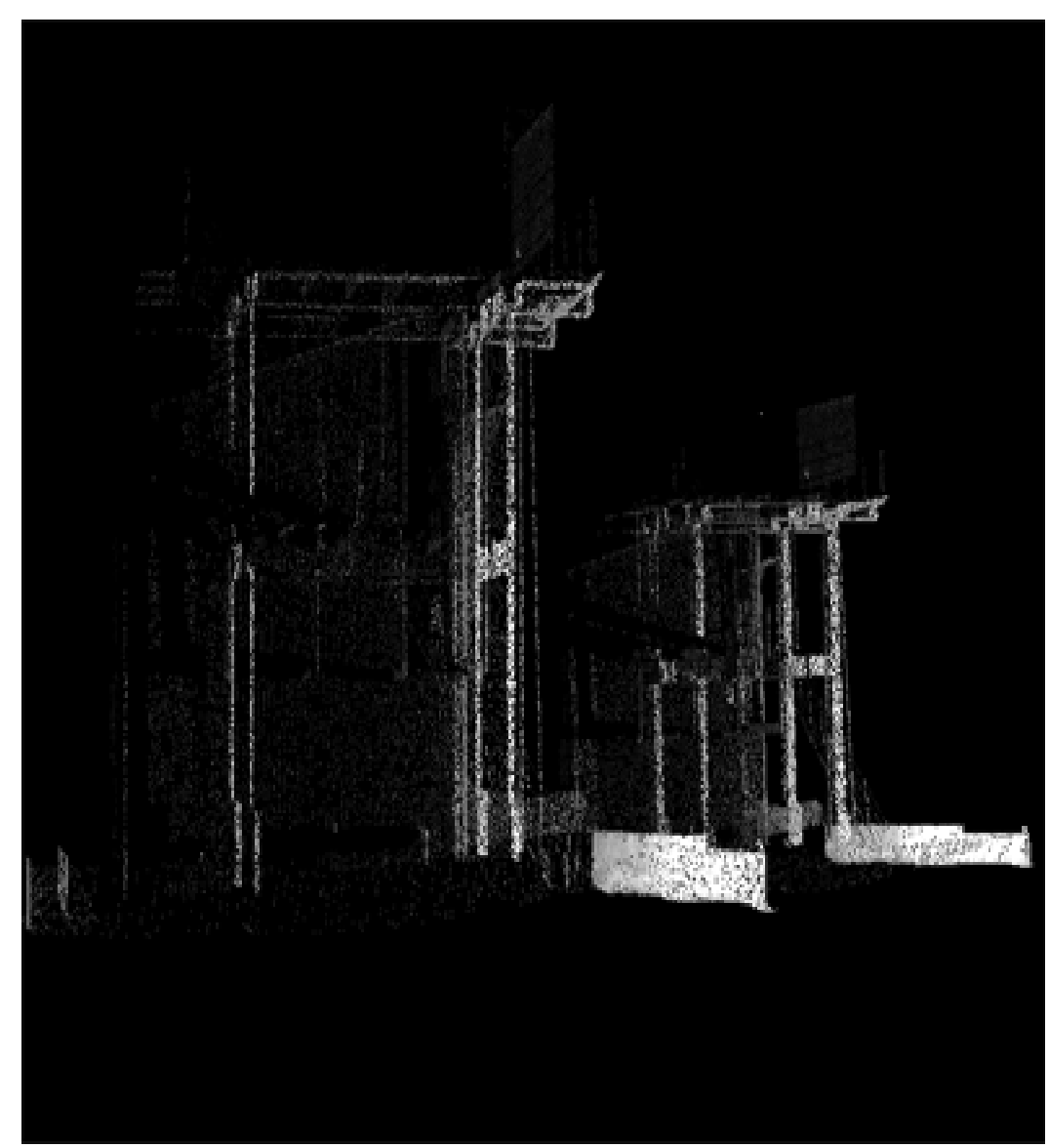

Before Registration

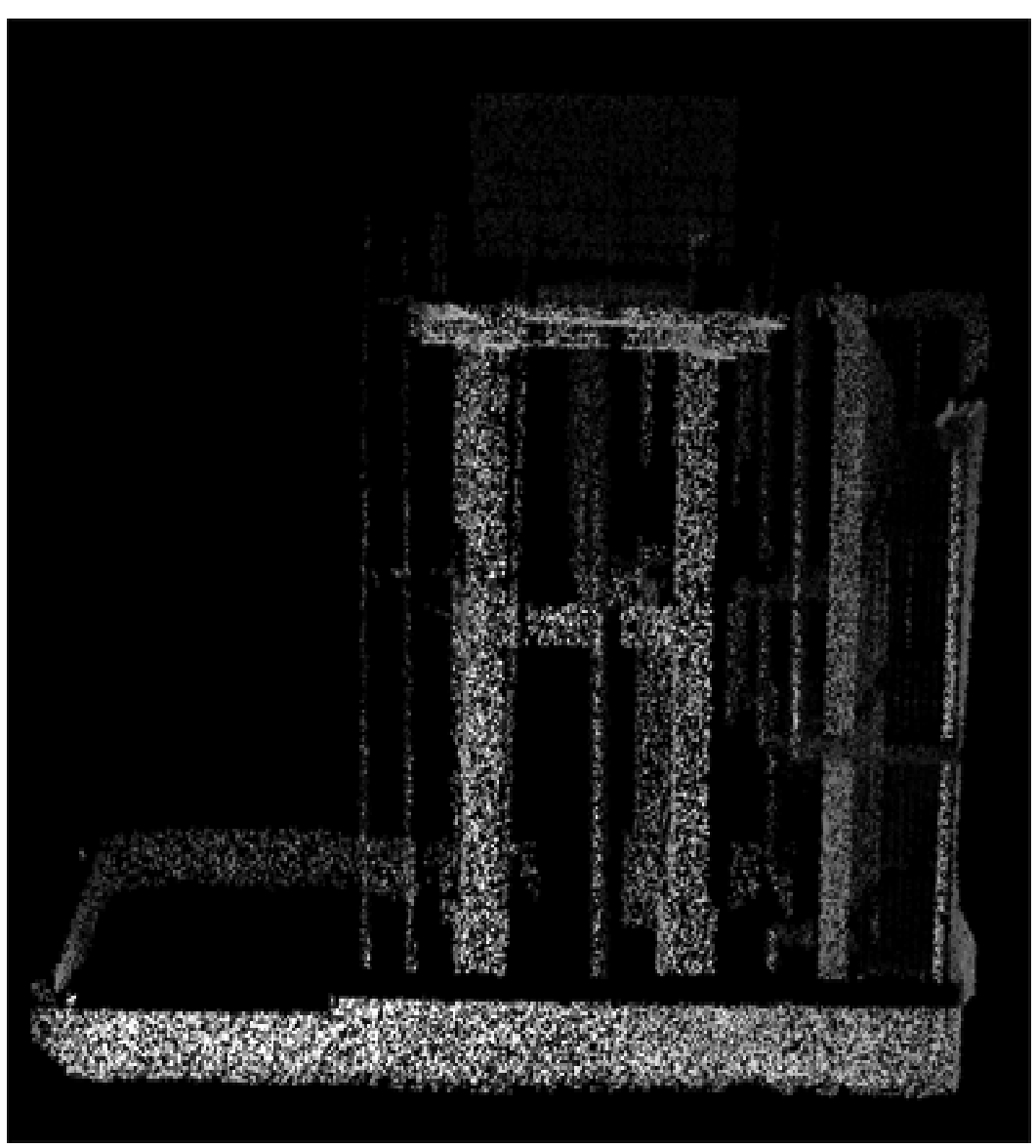

After Registration 


\section{Accuracy - Data Set 2}

\begin{tabular}{|c|c|c|c|}
\hline Parameter & True Value & Estimated Value & Error \\
\hline $\mathrm{Tx}$ & $10 \mathrm{~m}$ & $10.44 \mathrm{~m}$ & $-0.44 \mathrm{~m}$ \\
\hline $\mathrm{Ty}$ & $30 \mathrm{~m}$ & $29.886 \mathrm{~m}$ & $-0.114 \mathrm{~m}$ \\
\hline $\mathrm{Tz}$ & $-0.2 \mathrm{~m}$ & $-0.3 \mathrm{~m}$ & $0.1 \mathrm{~m}$ \\
\hline $\mathrm{Rx}$ & $0.01 \mathrm{rad}$ & $0.01 \mathrm{rad}$ & $0 \mathrm{rad}$ \\
\hline $\mathrm{Ry}$ & $-0.03 \mathrm{rad}$ & $-0.0299 \mathrm{rad}$ & $-0.0001 \mathrm{rad}$ \\
\hline $\mathrm{Rz}$ & $0.2 \mathrm{rad}$ & $0.2 \mathrm{rad}$ & $0 \mathrm{rad}$ \\
\hline Translation Error, || $\mathbf{E}_{\mathbf{t}}||$ & \multicolumn{2}{|c|}{$0.465 \mathrm{~m}$} \\
\hline \multicolumn{2}{|c|}{$0.0001 \mathrm{rad}$} \\
\hline
\end{tabular}

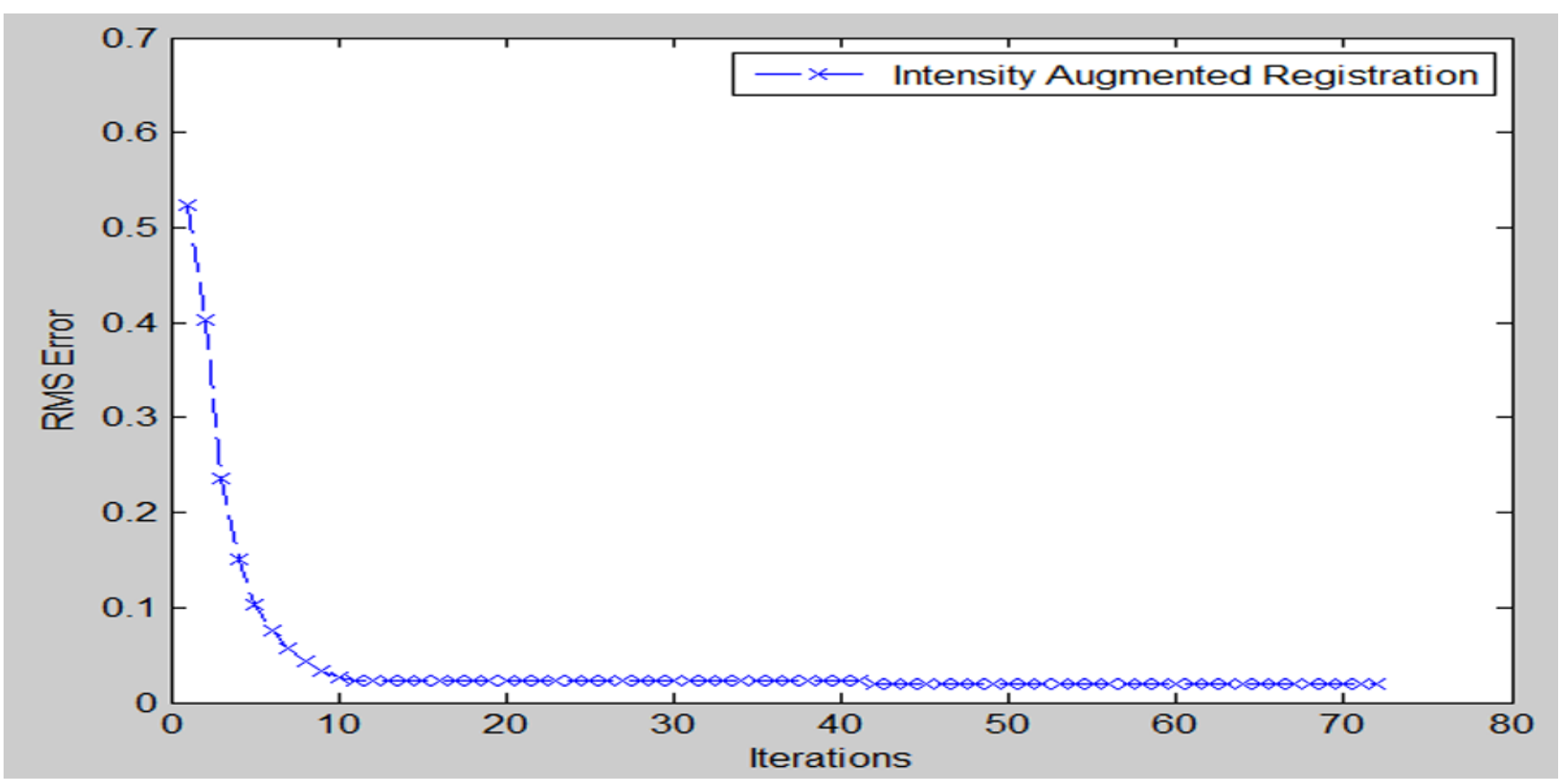




\section{Conclusion}

- Novel approach for Intensity Normalization

- New approach for Automatic LiDAR data registration

- Efficiency of the algorithm tested 


\section{Future Works}

- Testing on IDEs other than MATLAB

- Multiple data handling

- Intensity Normalization Algorithm

- Accuracy

- Flash LiDAR data processing (Lohani et al., 2013) 


\section{REFERENCES}

- Altuntas, C. (2011). An experimental study on registration three-dimensional range images using rangeand intensity data. International Archives of Photogrammetry, Remote Sensing and Spatial Information Sciences.

- Besl, P.J. and N.D. McKay (1992). A method for registration of 3D shapes. IEEE Transactions of Pattern Analysis and Machine Intelligence, Vol.14, 239-255, February,1992.

- Chen, Y. and G. Medoni (1992). Object modeling by registration of multiple range images. Image and vision Computing, Vol.10(3), 145-155.

- Fang, W., X. Huang, F. Zhang and D. Li (2015). Intensity correction of terrestrial laser scanning data by estimating laser transmission function. IEEE Transactions on Geoscience and Remote Sensing, 53(2), 942-951.

- Godin, G., M. Rioux and R. Baribeau (1994). Three-dimensional registration using range and intensity information. SPIE Videometrics III, 2350, 279-290

- Hebel, M. and U. Stilla (2007). Automatic registration of laser point clouds of urban areas. International Archives of Photogrammetry, Remote Sensing and Spatial Information Sciences, XXXVI(3/W49A), 13-18, 2007.

- Höfle, B. (2014). Radiometric correction of terrestrial LiDAR point cloud data for individual maize plant detection. IEEE Geoscience and Remote Sensing Letters, 11(1), 94-98. 


\section{REFERENCES}

- Johnson, A.E. and S.B. Kang (1997). Registration and integration of textured 3d data. International Conference on Recent Advances in 3D Digital Imaging and Modeling 17 (2): 234-241.

- Lohani, B. and S. Sasidharan (2013). Intensity Augmented ICP for registration of laser scanner point clouds. Proceedings of XXXII INCA International Congress on Cartography for Sustainable Earth Resource Management, Indian Cartographer, Vol. XXXII, 30-34.

- Lohani, B., S. Chacko, S. Ghosh and S. Sasidharan (2013). Surveillance system based on Flash LiDAR. Proceedings of XXXII INCA International Congress on Cartography for Sustainable Earth Resource Management, Indian Cartographer, Vol. XXXII, $77-85$.

- Masuda, T., K. Sakaue and N. Yokoya (1996). Registration and integration of multiple range images for 3D model construction. 13th International Conference on Pattern Recognition, Vol.10(3), 879-883, August 1996.

- Sasidharan, S. (2012). Intensity augmented ICP for 3D laser scanner point cloud registration. Master's thesis, Indian Institute of Technology Kanpur, IIT Kanpur, 6 2012. Accessed from P K Kelkar Library, IIT Kanpur.

- Sasidharan, S. (2016). A normalization scheme for terrestrial lidar intensity data by range and incidence angle. International Journal of Emerging Technology and Advanced Engineering, 6(5):322-328, 2016.

- Teo, T.A. and H.L. Yu (2015). Empirical radiometric normalization of road points from terrestrial mobile lidar system. Remote Sensing, 7(5), 6336-6357.

- Weinmann, M., M. Weinmann, S. Hinz and B. Jutzi (2011). Fast and automatic image-based registration of tls data. ISPRS Journal of Photogrammetry and Remote Sensing 66: S62-S70. 